\title{
ESTUDIO DE LA PRIMER AUTORIZACIÓN DE CONCENTRACIÓN DE EMPRESAS EN NICARAGUA BAJO EL RÉGIMEN DE LA LEY 601 Y SU REGLAMENTO
}

\author{
MSc. Enrique Villagra Gutiérrez \\ Profesor de la Universidad Centroamericana \\ evg@cablenet.com.ni
}

\begin{abstract}
Resumen: El trabajo de investigación que usted tiene en sus manos es un análisis exhaustivo sobre la primera concentración empresarial que se da en Nicaragua, cuya singularidad es que fue autorizada por la Administración Pública, en sede administrativa y responde a los criterios que establece la Ley 601 y su reglamento, Ley de Promoción de la Competencia. Este "estudio de casos y análisis jurisprudencial" como lo nomina la normativa interna de esta Universidad en su artículo 8 inc. f), tiene un particular interés para determinar si en la práctica se logró alcanzar las metas que se fijó la norma que consagra al Derecho de Competencia, que es nuevo en nuestro Ordenamiento Jurídico. El caso concreto estriba en la fusión de dos empresas avícolas, Tip Top y Pipasa, las cuales tienen participación accionaria de dos grandes transnacionales como es Cargill y Rica Foods. El monto de esta operación fue de aproximadamente 80 millones de dólares americanos con un impacto en el mercado relevante de un 61\%. Utilizando un análisis estructural y otro jurídico, determinamos que Nicaragua se ubica en los países que ejercen un control previo a las concentraciones empresariales en aras de salvaguardar el bien común y el interés social. Igualmente señalamos un alto grado de satisfacción por parte de PROCOMPETENCIA en el cumplimiento de la ley, pero igualmente puntualizamos los errores en que incurrieron. Este es el primer antecedente que marca una tendencia para todas aquellas empresas que en el futuro pretendan fusionarse. Queda de manifiesto en el estudio de esta Resolución Administrativa que no existe derogación tácita de normas sino una complementación legal al tratamiento que prescribe el Código de Comercio en la figura de la fusión, que la Ley 601 fortalece para que el Estado asuma una conducción de la economía nacional con un papel de mayor protagonismo, sin menoscabar los derechos a la libre empresa que consagra nuestra Constitución.
\end{abstract}

Summary: The research paper you have in your hands is a comprehensive analysis on the first enterprise concentration which took place in Nicaragua; its uniqueness is that it was authorized by the Public Administration, and administrative headquarters 
and it meets the criteria established by 601 Law and its regulations, the Law on Promotion of Competition. This "case study and analysis of cases" provided by the internal regulations of the University in Article 8 inc. f) has a particular interest to determine whether in practice they managed to achieve the goals it set the standard which establishes the Competition Law, which is new in our legal system. The case lies in the fusion of two poultry enterprises; Tip Top and Pipasa, which have shareholding of two large transnational companies such as Cargill and Rica Foods. The amount of this operation was approximately 80 million US dollars with a relevant impact in the market of $61 \%$. Using a structural and legal analysis, it was concluded that Nicaragua is considerate one of the countries which have a previous control over the enterprises concentrations in order to safeguard the common good and social interest. Likewise, it is shown the high level of satisfaction from PROCOMPETENCIA in complying with the law, but at the same time it was highlighted the mistakes made in the process. This is the first background marking a trend to all those enterprises which pretend to fusion. It is obvious in the study of the Administrative Provision that there is no tacit derogation of regulations but a legal complement to the issue prescribing the Commercial Code in the topic of fusion, which is enforced by the 601 Law with its purpose that the State adopts a more participative role in conducting the national economy without prejudice of the free enterprise rights enshrined in our Constitution.

Palabras clave: Derecho de competencia / empresas / concentración / Administración Pública

Key words: Competence Law / enterprises / concentration / Public Administration

Tabla de Contenido: I. Introducción; 1. Justificación y pertinencia del tema, 2. Consideraciones necesarias, 3. Del Sistema jurídico adoptado por Nicaragua, 3.1 De la opción tutelar del Estado en materia de Competencia, 3.2 De la opción del Estado de regular o no la concentración empresarial, II. Contrastes entre los sistemas de Costa Rica y Nicaragua en materia de Concentración; 1. Control Ex Post en Costa Rica. 2. Control Ex Ante en Nicaragua, III. Análisis Estructural de la primer Resolución Administrativa de Concentración Económica en Nicaragua; 1. Aclaraciones preliminares, 2. Cronología del Expediente, 2.1. De los sujetos solicitantes de la concentración, 2.1.1 De los compradores, 2.1.2. De los vendedores, 2.2. Síntesis cronológica del Expediente No. 0001-2010, Resolución Administrativa de Concentración Económica, 3. Análisis de forma o estructural de la Resolución, 3.1. Etapa de Iniciación, 3.1.1. Actos jurídicos preparatorios, 3.1.2. Acto de Iniciación del Procedimiento Administrativo, 3.2. Etapa de Desarrollo, 3.3. Etapa de Terminación, IV. Análisis Jurídico de la primer Resolución Administrativa de Concentración Económica en Nicaragua; 1. Del Control Ex Ante en la Resolución, 2. Autorización de un marco jurídico condicionado, 3. Sometimiento voluntario al levantamiento del Velo Societario, 4. Recopilación multisectorial de datos $e$ informaciones, 5. De las omisiones, imprecisiones y el Principio de Legalidad Administrativa en la Resolución, 5.1 Las omisiones de la Resolución, 5.2 Las imprecisiones de la Resolución, 5.3 El Principio de Legalidad Administrativa en la Resolución, V. Conclusiones; VI. Recomendaciones; VII. Lista de referencias; VIII. Anexos. 


\section{Introducción}

\section{Justificación y pertinencia del tema}

Siendo el Derecho de Competencia recientemente incorporado a nuestro Ordenamiento Jurídico, nos habíamos informado del contenido de esta disciplina del Derecho gracias a los aportes doctrinarios de los juristas extranjeros y nicaragüenses, el de éstos últimos representa una importante contribución para iniciar en el país una cultura jurídica, que aplicada a nuestra realidad, pueda y deba producir, consecuencias que se traduzcan en una mejor andanza de la economía nacional.

Residen en la Biblioteca "José Coronel Urtecho" de la Universidad Centroamericana, al menos dos estupendos trabajos académicos, el primero elaborado por las colegas Ruth Elizabeth Rojas y Ana Patricia Mena Flores (UCA, 2006) intitulado "Del Derecho de Competencia: El fenómeno de la concentración de empresas" que estudia al Derecho de la Competencia dando un énfasis al fenómeno de la concentración de empresas de una forma muy pormenorizada y minuciosa; cabe enfatizar que este estudio se efectuó cuando coexistían tres anteproyectos de ley en la Asamblea Nacional, en otras palabras la ley estaba en ciernes pero que profundizó esta Monografía de tal manera que es una especie de "biblia criolla" en materia de concentraciones. El segundo estudio, que consiste en un Paper defendido por el colega Melvin Javier Escobar Cerda, (UCA, 2009) y que fue distinguido por esta Casa de Estudios en su publicación en la Revista Encuentro No. 82 (Encuentro, 2009), versa sobre el "Control de las concentraciones económicas en el marco jurídico de la Ley 601, Ley de Promoción de la Competencia” y se trata de un cuidadoso estudio sobre los criterios de concentración que recogió el legislador nicaragüense en la Ley de Competencia, teniendo como contraste con la monografía anterior que en el primer estudio no existía la ley, y en este segundo no habían sido nombradas todavía las autoridades que constituirían el órgano de aplicación de esta legislación. De tal manera que, ambos trabajos son de gran valía pero por los tiempos de aparición de los mismos, no fue posible tratar la praxis en la aplicación de la legislación de competencia en lo que es en sí la concentración empresarial, en tanto no se había producido aún la concreción al caso particular, de los preceptos que en abstracto consigna la ley.

$\mathrm{Al}$ iniciar el presente trabajo de investigación se ha tenido el cuidado de no tratar nuevamente los aspectos que ya han sido aportados por los distinguidos colegas en la monografía y paper referidos, sino que, partiendo de una nueva realidad jurídica, como lo es el de la constitución de los miembros que integran la autoridad de PROCOMPETENCIA, es decir la Presidencia y Consejo Directivo; 
su consolidación como institución autónoma; y la capacitación debida de su reducido y eficaz recurso humano, que permitiera a la Institución ejercer su función administrativa a la altura de una ley que fue por muchos años, objeto de debates internos y posiciones contrapuestas con fundamentos doctrinales, que resultó a la postre en lo que es hoy nuestra legislación de Competencia, contenida en la Ley 601 y su Reglamento.

Este trabajo investigativo trata de la primer Resolución Administrativa de Concentración de Empresas que se ha producido en nuestro país, que fue dictada el día 24 de Marzo del año en curso, y que es la respuesta a la solicitud de dos compañías avícolas. Es la misión del trabajo en su desarrollo, procurar establecer si este primer fruto de la ley, logró o no alcanzar las expectativas jurídicas que se consagraron en la misma. Porque el paso que se da entre el texto de la ley y el caso en particular, es un ejercicio jurídico de interpretación, interpretación que la hace el órgano estatal destinado para ello, pero que en la lectura de esa interpretación que pasa necesariamente por un proceso de inteligencia por parte de los funcionarios que constituyen PROCOMPTENCIA, y de ese filtro puede resultar o la satisfacción de la hipótesis de ley o la frustración de la misma.

De tal manera que el lector por las razones ya expuestas, va a valorar no lo que correspondería a un estudio del Derecho de la Competencia; tampoco un tratado de Concentraciones de Empresas, que sería duplicidad al esfuerzo ya efectuado por otros colegas en esta Alma Mater. Lo que sí se intentará servir es un análisis exhaustivo de los criterios interpretativos de la autoridad de Competencia de Nicaragua, y que resultaron en la primer autorización de concentración empresarial contenida en la Resolución Administrativa 0001-2010 del 24 de Marzo del 2011.

\section{Consideraciones necesarias}

Resulta apropiado ubicarnos en cierto contexto para que sean omnicomprensivas las decisiones que se toman en esta primera autorización. Procuraremos suministrar algunas consideraciones que la doctrina y la ley obligan al órgano estatal a tomar en cuenta antes de tomar una postura que se refleje en su resolución.

La tutela del Estado hacia la economía nacional en materia del Derecho de la Competencia, está concebida bajo los cánones que recoge nuestra Constitución, es decir, un modelo económico que garantiza una economía de libre mercado con los ejercicios irrestrictos de la libertad de empresa, de la libre asociación y contratación, de una iniciativa privada que genere mayor riqueza a la nación; 
concepción ésta que sólo tiene cabida dentro de un Estado Social de Derecho. No obstante, esta cultura jurídica que debe ser aprehendida cada vez más por el Estado en sus distintos órganos así como por el sector privado en sus distintas escalas de empresas, pequeñas, medianas o grandes; es requerido que sea acompañada por una visión holística de cómo debe funcionar nuestro diseño jurídico y económico, la claridad de cuál es el sistema que abraza nuestro ordenamiento para el tratamiento de la economía nacional y hacia dónde quiere enrumbarla; la convicción de que la riqueza del país no puede ser medida por el fortalecimiento de las empresas ya existentes, sino por la ampliación y diversificación empresarial de una competencia que permitan a las empresas idear mecanismos cada vez más favorables para que, el servicio o bien que oferten, pueda tener el suficiente atractivo en el mercado que incline al consumidor final hacia su producción.

De tal manera que esta cultura jurídica en materia de Competencia puede lograrse no sólo remarcando aquellos artículos constitucionales que luego se desarrollan en otras leyes inferiores y que suelen enfatizar nada mas la libertad de empresa; porque ésta por sí sola, si no tuviera diques de contención legal, concentraría la riqueza en pocas manos, no permitiría la inclusión de nuevos proyectos económicos, asfixiaría a la competencia más débil y no ofertaría a la ciudadanía la libertad que ésta tiene de escoger entre varias opciones la que sea de su mayor conveniencia. Del tal forma que encontramos principios constitucionales yuxtapuestos, que demandan ser analizados dentro del Derecho de Competencia para alcanzar el equilibrio por medio del cual la libertad de empresa coexista jurídica y económicamente en una misma realidad nacional con la distribución de la riqueza y con los intereses legítimos del consumidor, es también necesario aceptar que los derechos no son absolutos y que tienen como límites aquellos que también la Constitución mandata y que obliga al Estado a velar por el Bien Común, como premisa esencial de su misión y razón de existir.

Este estudio investigativo pretende aportar un criterio valorativo de cómo se concreta el Derecho de la Competencia en un área que por sí misma no está tipificada como una conducta ilegal, como son las Concentraciones Empresariales; pero que si no son debidamente reguladas por el Estado, tendrán la tendencia por la misma dinámica propia del empresario, de procurar el beneficio propio con un potencial desmedro del consumidor al afectar el mercado relevante. De tal forma que partiendo de la primer autorización que en el ejercicio de sus atribuciones ha dictado el órgano estatal que regula la Competencia en Nicaragua, poder determinar si en su primer Resolución se realizó plenamente las hipótesis de hecho, los juicios hipotéticos previstos en la Ley 601, para así encontrar si hubo un pleno apego a los postulados que dicta la misma, y a partir de la praxis determinar qué modelo de competencia ha 
asumido el país, con sus beneficios y eventuales riesgos. Este primer antecedente reviste una capital importancia no sólo por el hecho jurídico que hace historia en nuestro acervo nacional, sino que a partir de los criterios que adoptó el ente estatal y del comportamiento de las empresas que se sometieron al imperio de la ley, podemos proyectar medidas que fortalezcan, agilicen e incluso incentiven, a empresas que de hecho están concentradas o que prevén estarlo para que ajustados a los lineamientos que el Estado de Nicaragua ha determinado, exista el convencimiento que a la postre resultan mayores perspectivas de crecimiento y de desarrollo que nos benefician a todos con una economía más saludable.

\section{Del sistema jurídico adoptado por Nicaragua}

\subsection{De la opción tutelar del Estado en materia de Competencia}

Quedan pocos países en nuestro continente que estén desprovistos de un marco regulatorio en materia de Derecho de la Competencia. En Nicaragua ha sido también un proceso prolongado para que nuestro legislador reconociera la necesidad de crear una ley determinada para esta materia que fuese capaz de regular la conducción de una sana economía nacional. Tras una prolongada espera de 10 años como lo documenta el Máster René Orúe (Orúe Cruz, 2008, p. 77), la Asamblea Nacional aprobó la Ley de Promoción de la Competencia cuya publicación está impresa en la Gaceta, diario oficial del 24 de Octubre del 2006, habiendo tenido una vacatio legis de ocho meses. Una vez alcanzada su plena vigencia en el 2007, a propuesta del Poder Ejecutivo la Asamblea Nacional ratifica a los miembros que conforman el Consejo Directivo, que es la autoridad máxima en donde se agota la vía administrativa del Instituto Nacional de Promoción de la Competencia, el día primero de abril del 2009. Siendo entonces hasta esta fecha que la concreción de las políticas relativas al Derecho de la Competencia queda, como expresaría Maurice Hauriou (Escorcia, 2002, p. 82) queda este derecho público encarnado en las personas administrativas investidas de poderes y derechos para manejar las políticas que entraña la Ley 601.

Nicaragua primeramente se sitúa en los países que han decidido tutelar la Competencia Empresarial, a nuestro juicio, con tres propósitos fundamentales: regular la conducta del empresario, proteger al consumidor final y velar por la bien andanza de la economía nacional. La opción asumida por nuestro país de ejercer un control legal, aunque tardíamente, sigue siendo una diferenciación en relación con la decisión de otras naciones que se han inclinado por la alternativa de dejar que sea la economía por sí sola quien determine sin restricción el andar macroeconómico de un país; dejando así los criterios de oferta y demanda sin ser regulados por el derecho interno, supeditando al no legislar, los criterios 
que competen a la responsabilidad del Estado en la conducción de la economía, bajo los parámetros de un mercado sin restricción donde el más poderoso, el mejor ubicado y el más expansionista, decida si tendrá o no competencia, qué se producirá y qué calidad de bienes y servicios, aparte de la fijación de los costos, recibirá el consumidor final al comprar los productos que le sean ofertados por aquella clase dominante económicamente.

\subsection{De la opción del Estado de regular o no la concentración empresarial}

No todo Estado que ha decido ejercer control sobre las empresas utilizando la disciplina del Derecho de Competencia tanto para regular la relación de una empresa con otra y de la relación de éstas con el consumidor final, ha incorporado necesariamente dentro de esa función tuitiva que ejerce, el de efectuar un control de las uniones o concentraciones que puedan suscitarse entre los agentes económicos del país. Esto es el dejar desregulado y al arbitrio de los criterios económicos el que dos o más empresas decidan concentrarse, aunque esta decisión implique un posicionamiento de dominio en el mercado relevante de una nación y un eventual detrimento contra empresas que se ubicarán después de dada la concentración, en una abierta desventaja que les impida el seguir operando; una opción más que puede suscitarse con la desregulación en esta área es el impedir que nuevas entidades empresariales ingresen al mercado para suministrarle al consumidor final más opciones en la adquisición de determinado bien o servicio.

Llama poderosamente la atención que en un país cuya legislación en materia de competencia ha sido de referencia para un modelo latinoamericano, como lo es Perú, sus legisladores omitieron regir la materia de concentración empresarial. Una omisión que no fue por descuido, sino que atiende a una decisión de Estado el apartarse de esta materia y dejar que sea el Derecho Privado el que la regule.

En el siguiente apartado destinamos una explicación que justifica la posición de Nicaragua al optar por el Control Ex Ante en materia de concentración empresarial.

\section{Contrastes entre los sistemas de Costa Rica y Nicaragua en materia de Concentración}

Cada país cuando incursiona en materia de Derecho de Competencia y en particular de Concentraciones de Empresas, no aplica sistemas homogéneos, sino que responden a criterios propios. De tal forma que encontramos legislaciones que definen por separado, cuáles son las prácticas anticompetitivas que serán perseguidas, utilizando un marco conceptual bastante claro. En 
contraste, la misma tipología es recogida en algunas leyes, de manera confusa, enunciándolas pero no definiéndolas, lo que a nuestro juicio poco abona en la certeza de criterios que utilizarán tanto los destinatarios de estas normas, como la misma autoridad que la aplique. Esto empieza a marcar diferencias sustanciales si tomamos como referencia la Ley No. 7472 de Costa Rica, con la Ley No. 601 de Nicaragua.

En el caso de la Concentración, Costa Rica a nuestro juicio engloba bajo ese mismo nombre, las fusiones, las concentraciones de sociedades, asociaciones, activos en general, que se efectúen entre competidores, clientes, proveedores. Vale la pena leer con detenimiento el artículo 16 de la ley costarricense para apreciar la forma en que se expresó el legislador:

\section{Artículo 16. Concentraciones.}

Se entiende por concentración la fusión, la adquisición del control o cualquier otro acto en virtud del cual se concentren las sociedades, las asociaciones, las acciones, el capital social, los fideicomisos o los activos en general, que se realicen entre competidores, proveedores, clientes u otros agentes económicos, con el objeto o efecto de disminuir, dañar o impedir la competencia o la libre concurrencia, respecto de bienes o servicios iguales, similares o sustancialmente relacionados.

En la investigación de las concentraciones, deben seguirse los criterios de medición de poder sustancial en el mercado relevante, establecidos en esta Ley, en relación con las prácticas monopolísticas relativas.

Es de nuestro parecer que hubiese sido de mejor claridad y por ende de mayor seguridad jurídica, si se hubiesen distinguido por separado varias de estas figuras, tales como las fusiones verticales, las horizontales, entre otras. O señalando, como aclara el Máster René Orúe (Orúe Cruz, 2008, p. 173), los criterios de diferenciación que distinguen a las empresas de las sociedades, precisando que las primeras se concentran, en cambio las segundas se fusionan. Conceptos que cuando desde un inicio quedan plasmados en la ley, son tratados por separados y resulta más funcional su aplicación por el grado de precisión.

Esta afirmación que hace el Profesor Orúe, contenida en su libro "Derecho de Competencia, una introducción”, la puntualiza el autor citando al académico Luis Miranda Serrano quien nos aclara que en las fusiones no son las empresas las que se funden, sino que los empresarios y más puntualmente los empresarios sociales, son los que desaparecen como entes económicos y jurídicamente independientes, permitiendo el surgimiento de un ente único que posee 
una personalidad jurídica distinta, que no coincide con la de las entidades participantes, o bien adopta la personalidad jurídica de una de las sociedades. Teniendo esto como resultado consecuente, que el nuevo ente, absorbe para sí, los patrimonios y los socios de las sociedades restantes que se extinguen.

\section{Control Ex Post en Costa Rica}

La ley costarricense al ser reglamentada, dispuso la comunicación voluntaria de concentraciones a la autoridad competente o sea Comisión para la Promoción de la Competencia, COPROCOM, como lo expresa la Sección Tercera. Por ende colegimos una de las principales diferencias que contrastan con nuestra ley nacional, ya que Costa Rica al asumir este modelo implementa el control ex post, las concentraciones se dan sin una previa autorización del ente gubernativo costarricense, y se acude a él voluntariamente, como una facultad potestativa que la ley permite a los empresarios, para que COPROCOM verifique únicamente que de la concentración ya consumada, se pueden generar efectos anticompetitivos que incurran en situaciones ilegales.

Aquí la Comisión, no autoriza sino que avala, no ordena sino que recomienda, la Comisión emite opinión y no resuelve con la suficiente potestad reglamentaria de obligar. Se debilita la ley cuando en el caso de potenciales conductas anticompetitivas producto de la concentración, no prohíbe, ni establece condiciones, sino que se limita nuevamente a recomendar que no se incurran en prácticas anticompetitivas, lo que a nuestro parecer, no se ejercer un efectivo control administrativo y se presta esa laxitud a que se cometan prácticas ilegales que serán sancionadas pero no prevenidas. Así lo inferimos de la lectura del artículo 39 del Reglamento No. 36234 que en la parte in fine se expresa así:

Si una concentración comunicada no contara con el aval de la COPROCOM o se le hubiere recomendado alguna medida correctiva que no fuera implementada, eso no prejuzgará sobre los efectos que pueda generar la concentración una vez realizada. La resolución favorable es independiente de la realización de otras prácticas monopolísticas prohibidas por esta ley, por lo que no releva de otras responsabilidades a los agentes económicos involucrados.

La omisión de comunicar una concentración en forma voluntaria no implica presunción sobre su ilegalidad.

Queda en evidencia que el Control Ex Post que se ejerce en Costa Rica, no conduce o controla la concentración, sino que sugiere los cambios tendientes 
a que ésta no incurra en hipótesis que sí están comprendidas como tipos de conducta ilegal.

\section{Control Ex Ante en Nicaragua}

La determinación del equipo que trabajó durante 10 años como mínimo el anteproyecto de ley en el área de Competencia, hizo acopio de los aspectos doctrinales pero también de las experiencias ya vividas en otros países de Latinoamérica y teniendo en consideración las ventajas y desventajas de la praxis, propusieron a los legisladores nacionales, una ley de competencia que resulta viable para nuestro entorno nicaragüense, que presta la seguridad jurídica a inversionistas en general, es una normativa que no pierde el norte de tener al consumidor como el destinatario final de su tutela, pero logra balancear por un lado la libertad de empresa de forma coadyuvante con el bien común, ambos principios dispersos en nuestra ley fundamental.

En materia de Concentración de Empresas, el sistema adoptado por Nicaragua responde al control denominado ex ante, esto es que bajo el imperio de la nueva ley, las empresas que en la búsqueda de mayores conveniencias y estrategias de mercado, desean concentrarse, fusionarse, o de alguna forma ligarse para alcanzar esa meta común, deben contar para ello con la autorización extendida por la autoridad de competencia como es PROCOMPETENCIA.

En contraste con la vecina Costa Rica, Nicaragua no espera las consecuencias que sufran los consumidores finales con las prácticas anticompetitivas que generen las concentraciones, para hasta ese entonces accionar la ley para detener y sancionar dichas prácticas. Nicaragua adopta un sistema, que bajo ninguna consideración limita las libertades de empresa, de asociación, de libre iniciativa que son concedidas por la Constitución Política a personas naturales y jurídicas, pero sin perder la misión que caracteriza al Estado y que estriba principalmente en velar por el bien común.

El Doctor Jesús Jusseth Herrera en un artículo publicado en la Revista de Derecho No. 9 del 2004, nominado "Análisis de la Constitución Económica Nicaragüense con Especial Referencia a la Libertad de Empresa", realiza una exégesis que evidencia que nuestra Carta Fundamental calza con los parámetros doctrinales que caracteriza a un Estado Social de Derecho, concebido éste como el último estadio en la concepción del Estado moderno. Alcanzar dicho ideal social y jurídico, exige matizar derechos que en doctrinas superadas fueron considerados como absolutos, pero que a la luz del Derecho moderno no pueden ser así. Subyace en nuestra Constitución Política, una Constitución Económica, nos dice el Dr. Herrera, y en efecto así es, de tal manera que los derechos 
propios de una economía de libre mercado, se ven limitados por los derechos de los otros y por aquellos que en aras del Orden Público Económico, establecen diversos postulados constitucionales y leyes ordinarias, como lo es la Ley 601, Ley de Promoción de la Competencia, cuyo objetivo no sólo radica en penar las conductas anticompetitivas, sino que es también un instrumento legal que en consonancia con el mandato constitucional disperso en los artículos 5, 44, 98, 99, 104, garantiza la libertad de empresa pero entendida ésta en el engranaje que conforma una función social que alcance la aspiración de una distribución justa de la riqueza, de una democracia que pase por el prisma de la igualdad económica. Para la consecución de estas metas, el Estado no puede delegar responsabilidades que garanticen las libertades y los límites de las mismas. Le es indelegable al Estado la conducción de nuestro sistema económico que brinde las garantías suficientes para ejercer plenamente los derechos económicos sin desmarcar éstos de la función social, del bien común, que al final de cuentas implica la suma de todos los intereses particulares.

$\mathrm{Al}$ amparo de las consideraciones anteriores, la Ley 601 al tratar el marco regulatorio de las concentraciones empresariales adopta el sistema de control denominado Ex Ante, que tiene como propósito proteger al consumidor de aquellos intentos de concentración, que de forma clara pretenden el abuso de la posición de dominio en el mercado, o que eventualmente den origen a prácticas colusivas y predatorias que finalmente repercutan negativamente tanto para la economía nacional pero también para la libertad de empresas propiamente dicha, pero que el resultado final lo recibe el destinatario último del eslabón económico que es el consumidor. El control Ex Ante, es por la exigencia del Estado para evitar que concentraciones empresariales o fusiones, terminen dañando al consumidor, a la competencia y a la sana economía.

PROCOMPETENCIA en contraste con lo que en Costa Rica se le faculta a COPROCOM, en Nicaragua no se avala una concentración, se autoriza; no se aconsejan cambios, se condicionan los cambios como requisito para la obtención de la autorización; tampoco emite opinión, sino que expresa el criterio de la ley por medio de una resolución que o autoriza, parcial o totalmente la concentración empresarial, la condiciona al cumplimiento de criterios legales, o incluso tiene la plena potestad de rechazar la intención de concentración y hasta ordenar la desconcentración que no haya sido efectuada bajo los criterios de la Ley 601 y su Reglamento. 


\section{Análisis Estructural de la primer Resolución Administrativa de Concentración Económica en Nicaragua}

\section{Aclaraciones preliminares}

Este apartado de la presente investigación amerita justificar la forma en que es presentado al lector para evitar caer en una descripción narrativa desprovista de un propósito ulterior; y tomando además en consideración la complejidad de la Resolución, la cual entremezcla criterios estrictamentelegales coninvestigaciones propias del área de la Economía, Contabilidad y otras disciplinas, las que por su naturaleza no son objeto de nuestro estudio. Cuando apreciamos esta primer concentración nos damos cuenta que su análisis exige una perspectiva holística de los momentos que anteceden a la solicitud de los agentes económicos, del tiempo que le tomó al órgano estatal en dictar su decisión y de las implicaciones que ésta tuvo.

Por ende, examinaremos esta primer Resolución de Concentración Económica bajos tres ángulos; debemos considerar la percepción que tuvo la ciudadanía en torno a la Resolución del 24 de Marzo del presente año, que trajo como consecuencia inmediata el que fuese recurrida por los organismos de defensa de los consumidores; esto implica rastrear esa opinión utilizando los distintos medios de comunicación que tienen registro del tema, teniendo el cuidado de no desviarnos del objeto de nuestro estudio. Otro ángulo será el de un análisis estructural de la resolución en sí, donde amerita observar el cumplimiento de los presupuestos de hecho que en abstracto recoge la ley y el reglamento y si éstos fueron aplicados al caso concreto. Este segundo aspecto reflejará un seguimiento cronológico a los términos de ley para su posterior valoración. En un tercero procuraremos relacionar los elementos de hecho y de derecho que tienen incidencia en el resultado de la concentración y si éstos llenaron las pretensiones de los agentes económicos interesados, hasta qué punto se satisfizo a las partes y si se salvaguardó el mandato consagrado en la Ley 601 y su Reglamento, Decreto No 79-2006.

\section{Cronología del Expediente}

\subsection{De los sujetos solicitantes de la concentración}

Con el propósito de hacer más comprensible la Resolución Administrativa debemos mencionar que comparecieron ante el Instituto Nacional de Promoción de la Competencia cuatro empresas que pretendían concentrarse. Dos de ellas en calidad de compradoras y dos como vendedoras. Dos empresas constituidas en el extranjero y dos en Nicaragua. 


\subsubsection{De los compradores}

Las empresas compradoras son:SUNVALLEY FOODSOFCENTRALAMERICA, $L t d$., sociedad que está constituida en la Mancomunidad de las Bahamas y de conformidad con la legislación de dicho Estado, debidamente registrada. Y la segunda compañía compradora es TIP TOP INDUSTRIAL, S. A., empresa cuya propietaria es precisamente SUN VALLEY FOODS OF CENTRAL AMERICA, Ltd.; Tip Top Industrial se conformó como sociedad anónima de acuerdo a lo que exigen las leyes de la República de Nicaragua por medio de Escritura Pública extendida por un notario nicaragüense e inscrita en el Registro Mercantil del Registro Público del Departamento de Masaya.

\subsubsection{De los vendedores}

Las empresas vendedoras son: la Sociedad RICA FOODS Inc., sociedad constituida bajo lo preceptuado por las leyes del Estado de Nevada, Estados Unidos de Norteamérica; Rica Foods es a su vez propietaria de la empresa costarricense, CORPORACIÓN PIPASA, S. A., con sede en Costa Rica e integrada de conformidad con las leyes de dicho país; esta Corporación PIPASA, S. A., es además propietaria de la cuarta compañía que comparece ante la Autoridad de Competencia para concentrarse, como lo es CORPORACIÓN PIPASA DE NICARAGUA, S. A., ésta última con sede en nuestro país y constituida bajo oficios notariales de profesional nicaragüense, y el amparo de nuestra legislación e inscrita en el Registro Público del Departamento de Managua.

Con la finalidad de no alterar la cronología y sólo aclarar quiénes son las empresas involucradas en la operación, nos referiremos a ellas más adelante y procedemos a reflejar los movimientos que se proyectan en el Expediente que estudiamos.

2.2. Síntesis cronológica del Expediente No. 0001-2010, Resolución Administrativa de Concentración Económica

\section{VISTOS RESULTA:}

1. 10 de Noviembre del 2010: Escrito de Solicitud.

2. 18 de Noviembre del 2010: Presentación de Poderes de Representación.

3. 22 de Noviembre del 2010: Auto de Iniciación, dando intervención a los representantes y designando a cuatro funcionarios para la tramitación y dictamen de la solicitud. 
4. 22 de Noviembre del 2010: Basados en el Art. 33 y 34 del Reglamento, se ordena subsanar lo siguiente:

a) ¿Cuáles son las empresas que se concentran directa e indirectamente?

b) Que los poderes de representación otorgados en el extranjero sean legalizados conforme a los procedimientos que establecen nuestras leyes, para que puedan surtir efectos jurídicos.

c) Adjuntar copia certificada o escritura de la Constitución de Sun Valley Foods of Central America Ltda.

d) Presentar: 1) Estados financieros, certificados por Contador Público Autorizado en Nicaragua, de Corporación Pipasa de Nicaragua $S$. $A . ; 2)$ Estados financieros del ejercicio fiscal anterior a la solicitud, es decir Julio 2009 a Julio 2010; y 3) Que dichos estados financieros sean presentados en el idioma oficial de la República.

e) Certificación de la composición del Capital Social de los agentes económicos participantes, detallando: 1) Situación actual; 2) Situación después de concentrarse; 3) Identificación de las personas que tienen el control actual; 4) Identificación de las personas que tendrán el control; 5) Lo requerido en idioma español; 6) Ante Notario Público.

f) Identificación de la fuente que efectuó la encuesta sobre la sustituibilidad de la demanda.

g) Requerimiento para razonar ante Notario Público, los documentos adjuntos.

5. 03 de Diciembre del 2010: Fueron subsanados por uno de los agentes económicos, los requisitos solicitados.

6. o9 de Diciembre del 2010: Fueron subsanados los requerimientos solicitados de la otra parte a concentrase.

7. 18 de Enero del 2011, 8:15 a.m.: De conformidad a los Arts. 46 de la Ley y 34 del Reglamento, la autoridad ordena a los representantes legales presentar a más tardar al segundo día hábil de notificado el auto, la siguiente información:

a) Detalle de los canales de distribución y Número de Clientes en los canales de distribución de los agentes económicos solicitantes (Cuántos son grandes, medianos y pequeños conforme los criterios de cada empresa).

b) Margen del precio de venta entregado al distribuidor y al detallista de los agentes económicos solicitantes.

c) Precio establecido al distribuidor y detallista en el último año, de los agentes económicos solicitantes. 
d) Porcentaje de venta entregado a los distribuidores y detallistas durante el último año, de los agentes económicos solicitantes.

e) Método de establecimiento de precio al distribuidor mayorista y al detallista, de los agentes económicos solicitantes.

f) Políticas de crédito ofrecidas a los canales de distribución (plazos y condiciones), de los agentes económicos solicitantes.

g) Detalle de la cartera de cuenta por cobrar relacionada con la política de crédito a los canales de distribución, de los agentes económicos solicitantes.

h) Detalle de exportaciones de productos del último año y planes en el corto y mediano plazo relacionados con exportación, de los agentes económicos solicitantes.

8. 18 de Enero del 2011, 2:40 p.m.: Se presentó la información requerida.

9. 27 de Enero del 2011: Se ordena presentar a más tardar a partir del segundo día hábil de notificado, la información siguiente:

a) Principales componentes de su fórmula de concentrado para la alimentación de pollo en libras por quintal.

b) Precios promedios mensuales de cada componente durante los años dos mil nueve, dos mil diez y Enero del dos mil once.

c) Informe de las razones por las cuales los medios de comunicación señalan escasez en el suministro de pollo en el mercado nicaragüense.

CONSIDERANDO: Diez considerandos preceden a la parte resolutiva y son tratados más adelante, en el presente capítulo.

POR TANTO: Fundamentación legal que enumera los artículos que facultan la resolución.

RESUELVE:

10. 24 de Marzo del 2011: La autoridad de PROCOMPETENCIA dicta Resolución Administrativa de Concentración Económica. La Autoridad resuelve de manera condicionada, otorgar la autorización de concentración económica, bajo los siguientes criterios:

11. Condiciones:

a) Libre Competencia: El deber del agente económico resultante de continuar participando en el mercado nacional respetando la libre competencia entre los diversos agentes participantes en el país. Y el 
abstenerse en incurrir en cualquier práctica anticompetitiva prevista en la Ley 601.

b) Mantenimiento y ampliación de canales de distribución: Esto es ordenar al agente económico resultante a continuar con el suministro de los canales mayoristas y minoristas que actualmente atiende; y a ampliar dichos canales a fin de promover el abastecimiento del mercado y mejorar la calidad. Seguimiento: Presentar un informe semestral por el lapso de tres años que deberá incluir factura de los diferentes canales atendidos y encuestas de satisfacción de distribuidores mayoristas y minoristas.

c) Fortalecimiento del Consumo Responsable y Seguridad Alimentaria: El agente económico resultante deberá entregar al Gobierno de Nicaragua por medio del Ministerio de Hacienda y Crédito Público y por el período de tres años, la cantidad de cincuenta mil dólares norteamericanos anualmente (US\$50,000.00), a fin que ésta cantidad sea dirigida a la asignación presupuestaria por medio de la Ley de Presupuesto General de la República, y destinada a las Asociaciones de Consumidores legalmente constituidas, para que éstas promuevan talleres de capacitación a sus asociados, promotores y representados, en materia de Consumo Responsable y Seguridad Alimentaria conforme lo mandata la Ley 182, Ley de Defensa de los Consumidores. Seguimiento: De esta contribución se deberá presentar informe anual a PROCOMPETENCIA de los fondos entregados durante el plazo fijado en esta condición.

d) Programa de Apoyo a Pequeños y Medianos Productores: Se le ordena al agente económico resultante continuar con los programas de apoyo a pequeños y medianos productores asociados, y ampliarlos en beneficio de los productores no asociados mediante visitas técnicas, distribución de documentos técnicos o informativos sobre el manejo de aves, además de talleres de capacitación sobre las prácticas del mercado avícola. Seguimiento: Deberá presentar por tres años ante PROCOMPETENCIA, informe cuantitativo y cualitativo anual sobre las visitas técnicas, distribución de documentos y talleres de capacitación, señalando los productores asociados y no asociados que la recibieron.

e) Estabilidad Laboral: El agente económico resultante deberá respetar la estabilidad laboral de los trabajadores de base de sus operaciones de producción y comercialización por un plazo de doce meses contados a partir de la fecha en que se materialice la concentración, sin perjuicio de las terminaciones por justa causa que señala la legislación laboral vigente $\mathrm{y}$ de las reestructuraciones que se realicen a niveles administrativos y gerenciales. Seguimiento: Presentar un informe semestral detallando el número de trabajadores de base de sus operaciones durante el plazo fijado para esta condición. 
f) Venta de la Marca Pollo Real: El agente económico resultante deberá ofrecer a la venta, la marca adquirida (Pollo Real), por el plazo de un año, a un tercer competidor potencial no nacional; la oferta de venta deberá realizarse mediante licitación pública, teniendo las empresas concentradas la facultad de fijar las condiciones y precios de venta, de conformidad a los principios de competencia y libre mercado. La oferta de venta debe ser publicitada en diversos medios de comunicaciones nacionales e internacionales, en la página web del agente económico resultante, así como en la página web de PROCOMPETENCIA. Dicha oferta de venta se entenderá sin perjuicio del derecho de los agentes concentrados de utilizar la marca durante el período establecido, vencido el período fijado, la condición expirará. Seguimiento: Una vez realizada la concentración, la empresa deberá presentar a PROCOMPETENCIA un informe trimestral que contenga evidencia de las publicaciones de la licitación pública ordenada.

g) Cláusula de No Competencia: Limitar el acuerdo de no competencia por un período máximo de treinta y seis meses (36) en el instrumento en que se formalice la concentración. Seguimiento: El agenten económico concentrado deberá presentar a PROCOMPETENCIA el documento en que se formalice la concentración, debidamente certificado ante Notario Público, a fin de verificar el cumplimiento de esta condición.

1. Prevenir al agente económico resultante de la concentración, que PROCOMPETENCIA podrá, en cualquier momento, verificar e impugnar la presente concentración económica, cuando tenga indicios de que la Autorización Condicionada fue obtenida con base a información falsa o incompleta, proporcionada por los agentes económicos solicitantes.

2. La presente resolución es susceptible de recurso de revisión ante esta Autoridad, el cual podrá ser interpuesto dentro del término de cinco (5) días hábiles, contados a partir de su notificación.

3. Notifíquese.

Hasta aquí corresponde a la síntesis del expediente al que se tuvo acceso, expediente que en virtud del Principio de Confidencialidad no refleja datos sensibles para las empresas a concentrarse, respetando igualmente el velo societario que sólo por disposición de ley y para conocimiento de la Autoridad de Competencia, queda expuesto. Que el expediente aquí condensado, hasta donde pudo ser consultado, tiene una extensión de treinta (30) folios tamaño carta. Y que el expediente completo está compartimentado en varios legajos, de tal manera que sólo los funcionarios autorizados tengan acceso al mismo. La 
confidencialidad está advertida en el artículo 30 de la Ley y 47 del Reglamento, so pena de responsabilidad penal y civil. De tal forma que, debe quedar consignado en la presente investigación que la consulta al expediente se efectuó de forma lícita y observando cabalmente las disposiciones de confidencialidad, y no se tuvo acceso, ni se pretendió acceder a la información privada, solicitada como confidencial por los interesados; que para esta investigación se dio fiel cumplimiento a la especial protección que la ley ordena para salvaguardar el velo societario y la confidencialidad.

\section{Análisis de forma o estructural de la Resolución}

El tratamiento de las concentraciones económicas previsto en la Ley 601 y su Reglamento, establece un procedimiento propio, en que prevé desde la forma de inicio, los plazos para cada etapa, hasta llegar a la parte resolutiva. Enuncia el Doctor Cairo Manuel López, al definir el Procedimiento Administrativo que "es aquel conjunto de principios de formalidades previas a la producción del Acto Administrativo y que tienden a regularlo desde su iniciación hasta el momento en que se dicta, su ejecución y los recursos que da a lugar en sede administrativa" (López, 1977).

En efecto nos encontramos frente a un procedimiento tipo, conocido doctrinalmente como Procedimiento Ordinario o de Gestión Administrativa (Arríen, 2009, p.44), que se caracteriza por tener tres etapas que son, iniciación, desarrollo y terminación. Estas etapas las vemos claramente reflejadas en el expediente objeto del análisis, correspondiendo la primera etapa, o sea de iniciación, a los Vistos Resulta que se aprecian en la cronología, esta parte de iniciación comprende desde la fecha de solicitud de Concentración Económica efectuada el día 10 de Noviembre del año 2010, o sea una iniciación a instancia del interesado, hasta los requerimientos solicitados por la autoridad, notificados el 27 de Enero del año 2011.

\subsection{Etapa de Iniciación}

\subsubsection{Actos jurídicos preparatorios}

Bajo los preceptos de la Ley 601, la etapa de iniciación no implica necesariamente la iniciación del procedimiento, sino que arranca con la iniciación del proceso u operación de concentración; por lo tanto debe diferenciarse que los Vistos Resulta están para apreciar el acto jurídico que corresponde a las partes, que inicia primeramente con la solicitud, que en este caso es por impulso de las partes interesadas, posterior se consigna en auto de iniciación donde se designan a los funcionarios que instruirán el proceso, cumpliendo con el artículo. 34 inc 
a) del Reglamento; y culmina esta etapa preparatoria con la satisfacción de los requerimientos del equipo técnico designado, hasta que éste tenga un panorama pleno de qué es lo que se está solicitando concretamente.

\subsubsection{Acto de Iniciación del Procedimiento Administrativo}

Para los efectos de la Ley 601 el inicio del procedimiento se establece una vez que se ha completado la información requerida, así lo mandata el artículo 35 del Reglamento. De tal forma que el cómputo es a partir de la subsanación de omisiones de la solicitud, o bien de información requerida que tienda al esclarecimiento de cualquier otro aspecto.

Así pues existe, $1^{\text {ro }}$. La presentación de solicitud de autorización, artículo 32 del Reglamento, la cual debe contener la información básica que describe el artículo 33 y que sirve como fundamento inicial para ilustrar a los funcionarios; $2^{\text {do }}$. Subsanación de Omisiones en la Solicitud, artículo 34, esta parte del procedimiento está prevista para complementar los requisitos que ordena el artículo 33 para los casos generales, y que al particularizarse en uno concreto, quedan imprecisiones en la información que deben ser subsanadas; $3^{\text {ro }}$. Prevé la normativa, las Facultades de Investigación de PROCOMPETENCIA, artículo 46 del Reglamento, en cualquier momento antes que se dicte la resolución final, y en efecto, en la presente Resolución se hizo requerido su aplicación, dada la complejidad de los estudios financieros, económicos y jurídicos que se conjugan.

Hasta esta altura del análisis estructural, lo comprendido desde la solicitud, así como las subsanaciones y las informaciones requeridas, no dan inicio al procedimiento; son apenas lo que en la doctrina se conocen como Actos Materiales de la Administración y que dentro de la clasificación de estos actos, Jorge Flavio Escorcia los ubica como Mayores, al respecto nos dice: “... constituyen antecedentes que condicionan la validez de los actos jurídicos, como por ejemplo, los estudios técnicos,...formación de proyectos, recopilación de datos... consecuencias económicas de un proyecto" (Escorcia, 2002, p. 158).

La observación que hay que señalar antes de concluir los comentarios de esta etapa, son en el sentido que el Expediente al que se accedió no refleja ninguna respuesta al último requerimiento de la Autoridad, no obstante y por el tracto sucesivo que exige la tramitación del expediente administrativo es de suponer que sí se respondió. No obstante y con el criterio de mayor claridad, debería señalarse de forma inequívoca y por medio de autos, el cierre de una etapa y la apertura de la otra, para reforzar la seguridad jurídica y que quede de manifiesto el respeto al debido proceso. 


\subsection{Etapa de Desarrollo}

Esta etapa descansa principalmente en los cuatro funcionarios nombrados, quienes tienen dos funciones primordiales, primero tramitar la solicitud y posterior, preparar un dictamen técnico de dicha solicitud. Para tramitar la solicitud, deberán cerciorarse que los datos presentados en el escrito de Solicitud de Autorización brinden al Instituto Nacional de Promoción de la Competencia, los insumos pertinentes y necesarios para establecer un juicio valorativo con los criterios que suministra la ley. Se concluye la solicitud cuando se ha presentado la información complementaria que sea requerida vía subsanación o vía presentación de informes. Y es a partir de este momento que inicia el procedimiento, habiendo tramitado la solicitud.

El segundo deber del Comité Técnico es la preparación de un dictamen técnico que se refleja en el expediente objeto de nuestro estudio en los considerandos; los diez considerandos son el desarrollo ordenado que conlleva corroborar los datos e informaciones que como consecuencia de la solicitud fueron aportados por los interesados; que se cumpla la verificación previa de lo aportado por los agentes económicos a concentrarse; describir pormenorizadamente la forma y esencia de la operación propuesta, lo cual pasa por el filtro de conocer legalmente quiénes son los agentes solicitantes, cómo están constituidos legalmente, bajo qué forma jurídica se conformaron, en qué país y bajo qué leyes se constituyeron, entre otros aspectos.

Lo que la doctrina denomina como Simples Actos de Administración, que los efectos jurídicos son a lo interno de la Administración y no trascienden de ella, en palabras de Escorcia "se agotan dentro de la administración" (Escorcia, 1992, p. 161), pero sucede que bajo los criterios que establece la Ley 601 y su Reglamento no son tan simples como los llama la teoría, todo lo contrario se convierten en un cruce de estudios interdisciplinarios que incluyen los jurídicos, legales, contables, financieros, de mercadotecnia, estudios de impacto económico, entre otros tantos, que complejizan el desempeño de estos cuatro funcionarios, que pueden si es necesario, valerse de informes periciales para lo cual el artículo 59 les faculta, con la salvedad que estos expertos no podrán tener vinculación o interés directo o indirecto. De otra manera, si no se les suministrara esta posibilidad a los cuatro funcionarios que instruyen la operación, sería una carga de imposible realización que se le impondría al Comité Técnico.

En el caso concreto los diez considerandos abordan aspectos medulares que son de naturaleza técnica, como serán apreciados por medio del siguiente esquema donde los contenidos son: 
A. Descripción de la Concentración:

1. Empresas Involucradas:

a) SUN VALLEY FOODS OF CENTRAL AMERICA LTD, TIP TOP INDUSTRIAL, S.A.

b) RICA FOODS INC., y CORPORACIÓN PIPASA DE NICARAGUA, S. A.

2. La operación de concentración.

B. Análisis de la Industria Avícola:

1. Tendencias de la Producción

2. Tendencias de Precios y márgenes

C. Mercado Relevante:

1. Mercado relevante del producto:

a) Sustituibilidad de la demanda

b) Sustituibilidad de la oferta

2. Mercado relevante geográfico.

D. Análisis del mercado:

1. Grado de concentración

2. Cálculos de índices de concentración

a) Antes de la concentración

b) Después de la operación de concentración

3. Índice de Concentración o Participación de Mercado en el Año 2009 para las agentes:

1. TIP TOP, S.A.

2. PIPASA

3. POLLO ESTRELLA

4. POLLO RICO

5. ARTESANAL

6. CA-PEQ (Central America Poultry Export Quota, Inc.) -es una compañía sin fines de lucro que fue formada para administrar las cuotas de cuadriles de pollo negociadas en el Tratado de Libre Comercio entre República

7. Dominicana, Centroamérica y Estados Unidos de América (CAFTA) en 2005 .

4. Cociente de Concentración por Participación de Mercado en el Año 2009 
5. Estructura Competitiva e Intensidad de Competencia en Precios

E. Evaluación de posibles efectos resultantes de la operación de concentración económica.

1. Efectos Unilaterales

2. Efectos Coordinados

3. Barreras a la entrada
a) Barreras administrativas, legales, y productivas
b) Barreras Arancelarias
c) Acceso a canales de distribución
d) Inversión necesaria y necesidad financiera para gastos operativos
e) Economía de escala
f) Exclusividad Tecnológica

4. Eficiencias (análisis de los beneficios directos como consecuencia de la concentración)

Después de leer el listado que antecede, probablemente para un letrado en el Derecho, el reflejo de estos criterios nos resulten agotadores en tanto no corresponden a nuestra disciplina, no obstante son la manifestación técnica de lo que la ley exige como el estudio exhaustivo del control ex ante, que utilizando medidas de Economía, Contabilidad, Mercadotecnia, y estudios de mercado, proyecciones, etcétera, permite al órgano de Competencia dictar una resolución que alcance los propósitos que dispone la ley.

Cabe señalar que los resultados de estas referencias, son parte de las reservas de la Resolución, en tanto son datos protegidos por la confidencialidad. Lo cual no sólo responde al manejo jurídico de los criterios internos en el manejo de una empresa, sino que también es parte de las fórmulas y secretos empresariales, que dentro de una estrategia de mercado, toda empresa guarda.

Así pues el Comité Técnico tiene como determinación de ley aportar un informe sobre el cual el Presidente del Instituto Nacional de Promoción de la Competencia y el Consejo Directivo fundamentarán una resolución motivada. No obstante hay que enfatizar que el resultado de lo actuado por los funcionarios designados para esta tramitación, cuya misión es instruir el proceso y actuar por delegación, tienen el peso de cumplir con las exigencias de la ley para determinar precisamente si los agentes solicitantes están o no sujetos a notificación y autorización; de ser sujetos a autorización, qué criterios para investigar les será aplicado al caso concreto, así como los que establecen el cálculo de ingresos brutos, analizar las descripciones de las concentraciones, sus objetivos y tipos; son todos ellos datos que no vinculan por sí mismos porque son para efectos 
internos que soportan de manera objetiva y técnica la decisión que la autoridad facultada toma frente a la solicitud.

Este comité logra su objetivo en tanto está autorizado para requerir de todo tipo de información que sea suficiente. Primeramente a los agentes solicitantes de la concentración: Tip Top, S. A., Pipasa de Nicaragua S. A., Sun Valley Foods of Central America Ltda. y Rica Foods, Inc. Segundo y de forma paralela a los agentes económicos que estén relacionados con la producción avícola y que son los competidores que operan dentro del mercado, a saber: Pollo Estrella, Pollo Rico, productores de carne de pollo artesanal e importadores de cuadriles inferiores. El Comité requiere de información igualmente a las compañías que operan en el mercado con productos sustitutos, tales como Walmart, La Colonia, Matadero San Martín, Nuevo Carnic. Pero igualmente y por ministerio de ley, PROCOMPETENCIA completa un panorama de mercado pleno y fehaciente con la información que puede requerir a cualquier entidad estatal en virtud de la Obligación de Colaboración dirigida a todos los organismos gubernamentales y autoridades en general, como literalmente se expresa el Art. 53 de la ley, el mismo que obliga a toda persona natural o jurídica a dar el apoyo y colaboración necesaria a fin que PROCOMPETENCIA cumpla con su cometido.

La observación en esta etapa es en el sentido que, llama poderosamente la atención que no se menciona por ninguna parte la existencia de la Empresa de Marca Pollo Real, que posteriormente en la Resolución se ordena o dispone sobre ella.

\subsection{Etapa de Terminación}

También denominada etapa resolutiva; y ya pormenorizada arriba. Esta contiene primeramente la fundamentación de ley o "POR TANTO", donde la autoridad basa la decisión y que en el caso particular son los artículos 24, 25, 27, 28 de la Ley 601 "Ley de Promoción de la Competencia” y los artículos 27, 31, 32, 33, 34, 35, 36, 38, 40 y 41 del Decreto Número 79-2006 Reglamento a la Ley 601.

Finalmente dentro de este análisis estructural, la parte dispositiva está compuesta de cuatro segmentos. El primero decide otorgar la autorización a los cuatro agentes económicos que la solicitaron bajo siete condiciones, todas obligatorias, y seis de ellas sujetas a comprobaciones de cumplimiento también obligatorias. El segundo es una prevención al agente económico resultante, de verificar y revocar la presente Resolución si se tiene indicios de falsa la información suministrada por los agentes económicos solicitantes. El tercer segmento indica el recurso a aplicar por las partes interesadas en caso de no estar conforme. Y como última y cuarta parte es la orden de notificar. 
Encontramos que se cumple con puntualidad y esmero los procedimientos establecidos por la Ley y el Reglamento, así como los aspectos que la doctrina sostiene para referirse al Procedimiento Ordinario o de Gestión Administrativa.

\subsection{Interposiciones de Recursos de Revisión y Apelación en la Vía Administrativa}

Este acápite es para hacer un paréntesis en el análisis de la Resolución, con el propósito de completar la información y manifestar que la Autorización de Concentración fue una Resolución recurrida (La Prensa, 10 de Abril del 2011), tanto con la utilización del Recurso de Revisión como de Apelación por parte del representante legal del INDEC, Instituto Nacional para la Promoción y Defensa de los Derechos de los Consumidores. Y tan sólo queremos acotar que tanto INDEC supo demostrar su interés legítimo, como PROCOMPETENCIA el reconocérselo, y que a nuestro criterio fue un actuar correcto y justamente apegado a derecho. Nos referiremos más ampliamente a este tema en el capítulo siguiente, en el acápite 5.2 d).

Hasta este punto del trabajo, hemos procurado acotar los aspectos de forma en que se expresó esta Resolución Administrativa que nos ocupa. Procedemos entonces a otro tipo de consideraciones que se circunscriben a un análisis ya no de forma, sino de fondo, a un análisis jurídico.

\section{Análisis Jurídico de la primer Resolución Administrativa de Concentración Económica en Nicaragua}

El primer reto que a este parecer implicaba la primer Resolución Administrativa de Concentración de Empresas, radica en el balance de aplicar la ley, y por ende la orden de regular que lleva explícita la misma, esto sobre la decisión que cuatro empresas tomaron para concentrarse, buscando necesariamente una mejor conveniencia a sus intereses corporativos; por otra parte, el criterio de la Resolución de mantener a su vez el respeto a la libertad de empresa, la libre iniciativa económica, el reconocimiento por parte del Estado a las distintitas formas de propiedad, el libre acceso al mercado, entre otros valores jurídicos que celosamente consagra nuestra Constitución Política, estos mismos que el Doctor Herrera denomina como constitución económica nicaragüense (Herrera-2004), propias de las constituciones postmodernas.

Esta primera autorización de concentración tenía como reto cumplir con el mandato de ley, como un deber ineludible; respetar la libertad de empresa y garantizar la libertad de mercado, que pasa por la libre competencia; y por encima de estos criterios, cumplir con la finalidad esencial del Estado que es 
velar por el bien común, ese interés público que limita algunas libertades y garantías constitucionales.

El análisis de la Resolución ooo1-2010, no corresponde a un análisis de la Ley 601, tampoco es un análisis de las interpretaciones a la misma, es esencialmente un análisis de la aplicación de la Ley 601 al caso concreto que es la autorización a una concentración de empresas avícolas. Y bajo ese criterio es que debe estudiarse y comprenderse para determinar los aciertos de este antecedente que marca una tendencia; en este análisis se debe procurar señalar objetivamente los errores o desaciertos en que ésta incurrió.

Cabe cuestionarse si con la aplicación de la ley en la materia de concentraciones, se concretó el propósito del legislador; si con ella se tuteló el interés público de la economía nacional, y si esta resolución administrativa trajo como consecuencia un estímulo a los agentes económicos que la solicitaron o si por el contrario, desmotivó sus planes de crecimiento. También cabe preguntarse cómo utilizó la autoridad la función administrativa que se le confirió, si fue oportuna y con mérito, -ese elemento constitutivo del acto administrativo-. Si su decisión resultó ser ajustada a los criterios de la ley y al de la pretensión de las partes si actúan en el marco de la misma; o si en cambio su respuesta fue ultra petita, es decir, otorgando más de lo que fue solicitado, o citra petita, concediendo algo diferente a lo pedido o la tercer opción, infra petita, que es el otorgar menos de lo pedido por las partes.

Para responder estas consideraciones resulta muy pertinente la lección No. 9 del Manual de Derecho Mercantil del Profesor Orúe, que dedica esa lección precisamente a reflexionar sobre el Derecho de Competencia, al respecto nos recuerda que no corresponde al Derecho de Competencia regular el acceso al mercado, por tanto esto es propio del Derecho Administrativo; que debe abstenerse el Derecho de la Competencia en regular los contratos porque sería invadir el campo propio del Derecho Mercantil; y lo que sí le corresponde es regular la actuación externa del empresario, siendo la competencia el marco jurídico y económico de esa actividad externa. Esta necesaria ubicación de la esfera de acción del Derecho de la Competencia nos conduce necesariamente a considerar si los preceptos abstractos de la Ley 601 y su Reglamento, al momento de la praxis jurídica fueron plasmados con algún grado de suceso en esta primer concentración que se autoriza.

Es de este criterio que consideramos que, lejos de invadir otras disciplinas normativas y lejos también de vulnerar ese conjunto de libertades y garantías que son tuteladas por lo que hoy denominamos como Constitución Económica, esta Resolución 0001-2010 no termina prescribiendo a las partes qué hacer 
con sus empresas ni con sus intenciones de mercado, en otras palabras se cuida en sus términos la resolución en no socavar el derecho de autonomía de las personas jurídicas, pero sí les indica el camino a seguir para alcanzar sus propósitos empresariales, cómo transitar legalmente por ese camino y lo que deben evitar en dicho tránsito para no incurrir, no tanto en el monopolio que no es perseguido por la ley, sino que advierte al agente resultante que no caiga en prácticas anticompetitivas porque éstas sí son perseguidas por el Derecho de la Competencia. Y son perseguidas no sólo por ser conductas tipificadas por el derecho positivo nacional, sino porque como diría en esa misma cita el Doctor Orúe, el Derecho de Competencia "protege la libertad de competencia con el fin de asegurar que los consumidores y usuarios puedan optar por la alternativa que más les convenga” (Orúe, 2008, p.178).

Cuando la Ley 601 indica que, para efectos de la misma se imputarán como concentraciones, procede de forma seguida a señalar al menos cinco distintas posibilidades para los agentes solicitantes, las cuales son: la fusión, la adquisición, los acuerdos, los convenios, la integración y la combinación, todas estas figuras referidas a los negocios que en su totalidad o parcialmente, y como consecuencia de la concentración, tengan como resultante que los agentes solicitantes dejen de ser independientes. Ahora bien, ¿̇son éstas figuras señaladas en la ley, figuras societarias típicas o atípicas, o son en todo caso, distintos contenidos de negocios jurídicos que serán adoptados por el instrumento legal que las personas jurídicas interesadas decidan? La respuesta a qué debe considerarse concentración para efectos de la Ley 601 es contundente en la Resolución, la ley no está redactada en el sentido de obligar a los solicitantes a adoptar cuál será el contrato o la forma societaria que tendrán que utilizar para concentrarse, sino regula cómo debe de ser ese nuevo negocio que establecerán las partes como resultante de la concentración, para que ése sea un negocio jurídico y además legal.

Y frente a la solicitud de estas empresas avícolas, la Resolución les responde diciendo que para que su concentración esté de conformidad con la ley, deben observar las condiciones que se establecen para no incurrir en prácticas anticompetitivas, y sea cual fuere la forma en que se concretará su negocio jurídico, el fin que persigue no debe vulnerar los derechos laborales de empleados y funcionarios, todo lo contrario, debe mantener la estabilidad; tampoco debe cerrar los canales de distribución del comercio avícola, sino ampliarlos; que cuando "se materialice la concentración" -como en la página 29 se refiere la Resolución-, que el agente resultante mantenga la libre competencia evitando así sacar del mercado a los agentes ya existentes o el obstaculizar que nuevos agentes se consoliden creando barreras a la entrada a nuevos competidores. En otras palabras la Resolución indica el cauce jurídico a seguir y no el vehículo legal 
que las empresas solicitantes utilizarán; la resolución al establecer condiciones no está obligando con ellas a que los interesados continúen con la concentración, pueden si así lo determinan, abandonar sus pretensiones sin verse coaccionados por el órgano estatal para asumirlas como decisión propia de los empresarios. La Resolución les establece con fuerza de ley que las empresas avícolas solicitantes, si desean concretar su intención de concentrarse, deben hacerlo pero bajo las indicaciones precisas que ordena y observando las condiciones sin las cuales no puede nacer el agente resultante o concentrado.

\section{Del Control Ex Ante en la Resolución}

Ahora es válido cuestionarse el por qué otorgar una autorización para concentrarse, ¿si siempre es requerido? y el por qué en el caso concreto sí ameritó autorización. La razón se explica con los dos parámetros que establece el Art. 26 de la Ley 601, al mandatar que requerirán el permiso o autorización aquellas empresas que al concentrarse sobrepasen el $25 \%$ del mercado relevante, en el caso concreto el agente resultante llegaría al 61\% del mercado relevante del mercado avícola (La Prensa, Abril 10, 2011), cifra no revelada oficialmente pero que sí supera el 25\%. Y el segundo parámetro que determina la ley es cuando los agentes económicos a concentrarse, en este caso las compañías nacionales Tip Top y Pipasa, juntas tengan ingresos brutos superiores a 642,857 salarios mínimos, criterio de ley que también sobrepasan. Estas dos razones justifican el permiso previo para concentrarse, quedando dirimido si es la ley o el reglamento el que establece el Control Ex Ante, o no. Con esta primer resolución se despeja esa duda que deja planteada el Profesor Orúe en su obra "Derecho de Competencia, una introducción”, que en su página 200, tercer párrafo, cuando está desarrollando en su interpretación a la Ley 601 y su Reglamento, sus reservas en tanto si el Control Ex Ante lo desarrolla la Ley o el Reglamento, dice él: "queda a criterio de la autoridad de aplicación determinar su significado". Es por tanto valiosa la resolución objeto de estudio, que también despeja las válidas incógnitas suscitadas. En esta primer autorización de concentración de poder económico queda claro que el artículo 24 de la Ley describe qué se entenderá por concentración; en la parte in fine del mismo aclara que estas concentraciones que describió no requieren ni de notificación ante PROCOMPENTENCIA, ni de autorización. Y en el Art. 25 de la misma ley, indica cuáles son los dos supuestos en que la operación de concentrarse, sí exige el Control Ex Ante como requisito sine qua non.

Ya que no toda unión de empresas es concentración, ni requieren de permiso, como lo explica el salvadoreño Mauricio Herrera: "Sin embargo, no todas las compras o fusiones terminan en empresas más grandes o con una mayor variedad de productos. Algunas de ellas únicamente buscan la consolidación 
de sus propios negocios. Esto significa que puede tratarse de una simple reestructuración de un grupo empresarial que desea reducir el número de tipos legales -o empresas- bajo su dirección". (Herrera, 2009) Concluimos que para los efectos de nuestra ley, toda concentración deviene de una fusión, adquisición, acuerdos, convenios, integraciones o combinaciones; pero no toda fusión, adquisición, acuerdos, convenios, integraciones o combinaciones es necesariamente una concentración.

\section{Autorización de un marco jurídico condicionado}

Por lo tanto, ¿qué autorizó entonces PROCOMPETENCIA a las empresas avícolas?, autorizó un marco jurídico regulado particularmente en la materia de Competencia, en donde podrán, si así lo desean los agentes solicitantes, concentrarse bajo la forma que estimen pertinentes para la consecución de sus fines. Y como todo marco jurídico regulatorio establece lo que se puede hacer y lo que no se debe hacer, y para regular esos deberes impone ciertas condiciones que estarán sujetas a controles o seguimientos periódicos para verificar si se están cumpliendo. Y ésta, es a juicio de esta autoría, la parte toral de la resolución: el de no indicar quién de los cuatro solicitantes, va a ser el agente nuevo, ni qué mecanismo legal utilizarán para la operación de unión o integración, sino cuál es el marco jurídico al que el agente resultante estará obligado a observar so pena de ser sancionado o hasta desconcentrado.

\section{Sometimiento voluntario al levantamiento del Velo Societario}

Por otra parte, requiere una mención necesaria el respeto que denota la Resolución a la autonomía patrimonial de las personas jurídicas que solicitan la autorización. Definitivamente no puede existir otra vía para determinar el verdadero propósito de las partes, ni conocer de sus ganancias, su organización interna, quiénes son sus socios y en qué proporción lo son, tampoco se podría conocer de sus manejos financieros, estados de cuentas y muchos otros aspectos si no se alterara lo que en doctrina se denomina como "dogma del hermetismo de la persona jurídica”. Estamos acostumbrados al levantamiento del Velo Societario cuando lo ordena un Juez o Tribunal de Justicia para evitar o conocer de acciones fraudulentas.

Este es otro aspecto novedoso que refleja la Resolución y que está expuesto en los requerimientos que acompañan a la Solicitud y posteriormente en las subsanaciones e informes que solicita PROCOMPETENCIA y que están en los Visto Resulta. El desarrollo de los diez considerandos que como indicamos, motivan la parte resolutiva, no se hubiesen podido consolidar sino se hubiese dado el mantenimiento del "dogma del hermetismo" como un derecho de las 
personas jurídicas y una garantía a su seguridad jurídica; y éste se supera no por orden judicial, ni como una imposición o decisión de sumo imperio por parte del Estado representado en el Instituto que vela por la competencia, se logra flanquear el velo societario porque las partes están anuentes a hacerlo, porque constituye un requisito para extender la autorización, que es conocer a fondo todo lo relativo a las empresas solicitantes.

El Velo Societario como tal, es una figura que despierta acérrimas discusiones en la doctrina, así fue estudiado en la Maestría en Derecho de empresas, en el Módulo II impartido por la Profesora Neylia Abboud, y que se consigna en el dossier que el levantamiento del velo puede darse en diversos ámbitos legales, como pueden serlo el laboral, el mercantil, el tributario, y en nuestro caso particular el ámbito de competencia; que no es exclusivo del Juez sino que también es facultado por ministerio de ley para determinados funcionarios. (Abboud, 2010, p.25).

Entre las razones que tiene el Juez para ordenar por medio de sentencia levantar el velo societario y vulnerar así el hermetismo de la persona jurídica, en comparación a las razones que justifican a la Ley 601 y su Reglamento para que la Autoridad en determinados casos como lo es el de concentración, requiera a los solicitantes que expongan a su empresa y a sus socios, mutatis mutandi tiene el mismo efecto, bien sea por sentencia judicial o por mandato de la ley a una autoridad administrativa, que es develar la información necesaria para ponerla a disposición y que sea así apreciada por la autoridad, a fin de que ésta pueda proveer conforme la finalidad que la ley pretende. Y que en el tema del Derecho de Competencia no es el fraude societario sino en todo caso, el evitar fraude de Ley, que en la concentración debe garantizar que no se autorice por desconocimiento, el surgimiento de una posición de dominio en el mercado que sea tan fuerte, que en la práctica implique que en virtud de la misma autorización y por no tener la autoridad conocimiento pleno de la información de las empresas, se violenten conductas que son contrarias al propósito de la Ley 601 y su Reglamento.

\section{Recopilación multisectorial de datos e informaciones}

Sin embargo no fueron suficientes la informaciones que brindaron las empresas avícolas al órgano de competencia, para suministrar los criterios plenos que autorizan la presente concentración, se requirió también contrastar los datos dados con los de los agentes dentro del ramo avícola que ya están actualmente funcionando en el mercado, el panorama se complementa con la competencia comercial de los solicitantes, así tenemos que dan información para instruir la resolución: Pollo Estrella, Pollo Rico, CAPEQ, artesanal; y complementan estos 
datos, creando un todo suficiente, los requerimientos que se hizo a instancias estatales como son las siguientes: Ministerio de Fomento, Industria y Comercio, MIFIC; Ministerio Agropecuario y Forestal; Banco Central de Nicaragua.

\section{De las omisiones, imprecisiones y el Principio de Legalidad en la Resolución}

Este análisis se encontraría inconcluso si no se hicieran algunos señalamientos u objeciones con el debido fundamento sobre la Resolución, que es hoy objeto de este estudio. Es pertinente hacer la salvedad que en nuestra opinión se alcanzó en esta primer autorización de concentraciones los objetivos que la ley se propuso en la aplicación a un caso concreto. Si bien el grado de satisfacción a los propósitos de la ley es alto, no obstante en el transcurso del trabajo observamos varios tipos de errores. Errores que son comprensibles cuando nos encontramos frente al ejercicio que implica el poner en práctica esta Ley 601 en materia de concentraciones, y que precisamente esta concentración avícola con que se estrenó la normativa es por sí misma muy compleja, y esto lo fundamentamos con algunos datos que de conformidad con los medios de comunicación y organismos de defensa del consumidor nos indican que ésta fue una operación de más de 80 millones de dólares americanos, que la fusión de las empresas tienen un grado de participación de mercado que alcanza el 61\%, que se hizo ordenadamente en un lapso de 144 días hábiles de un máximo de 210 que presupuesta la ley, esta última cifra corresponde a la cantidad de días que abarcan todas las probables incidencias y plazos, que no necesariamente se dieron en esta operación. Esta misión que descansó en los hombros de cuatro funcionarios para analizar e instruir el procedimiento y que nos obliga, no a incurrir en condescendencias que no son propias de la academia, pero si contextualizar debidamente que cuando analizamos las funciones de los diversos órganos del Estado notamos lentitud en los trámites, falta de diligencia, ostracismo en la gestión pública, y en contraste tenemos necesariamente que concluir que en PROCOMPETENCIA se obró con eficiencia, pese a los errores que a continuación señalaremos.

Estos errores los dividiremos en tres grupos para no entremezclarlos desordenadamente y haremos un comentario sucinto al respecto. En realidad nos tienta subtitular bajo los nombres de: Lo que no dijo; lo que mal dijo; y lo que no debió haber dicho la Resolución; pero por la estética del trabajo y por respeto a los términos académicos, los nominaremos así: 


\subsection{Las omisiones de la Resolución}

a) En la parte in fine del artículo 2060 del Código de Procedimiento Civil, que dicho sea de paso es de conformidad con el artículo 51 de la Ley de Promoción de la Competencia una norma procesal supletoria para los vacíos de la misma, establece el Código de Procedimiento Civil que cuando se dicta una sentencia, en este caso entiéndase una resolución, la única parte que vincula es decir, que produce efectos jurídicos, no son los Vistos Resulta, ni tampoco los Considerandos, sino la Parte Resolutiva; este punto está abundantemente aclarado en diversas Sentencias de la Corte Suprema de Justicia. No restan ni la necesidad ni tampoco la pertinencia del contenido de los Considerandos, en tanto que ilustran y sustentan la resolución o sentencia, pero sí aclaran que incluso de darse una contradicción entre lo que se consigne en los Considerandos y lo que indique la Parte Resolutiva, será el contenido de ésta lo único que obligará.

Dicho esto, apreciamos que en la Parte Resolutiva de la Resolución o0012010, no se indica qué tipo de autorización se está otorgando. Si ésta es una fusión horizontal, vertical o de otra índole. Constatamos que en los Considerandos se aclara que es una fusión vertical y horizontal pero esto debió haber quedado escrito en la parte resolutiva, para efectos tanto de los otros agentes competidores del mercado en el mismo producto, así como de los consumidores. Se debió haber establecido con claridad qué tipo de fusión o concentración se autorizó.

b) Ahora con la lógica inversa, en la parte que consultamos y de la cual tuvimos acceso al Expediente que reiteramos que está protegido para salvaguardar la confidencialidad, no apreciamos que se hiciera alusión de la Marca Adquirida "Pollo Real", cuando debió haberse desarrollado en los Considerandos para mantener así la congruencia de la decisión. No obstante se traslada, a quien estudia el expediente, la impresión que fue un tópico que surgió en su tratamiento de forma tardía, y que irrumpió en la parte resolutiva sin mediar consideraciones que hiciesen comprensible tal determinación. Posteriormente volveremos a tratar este tema de la Marca Adquirida más adelante y con otro enfoque.

c) La concentración que se autoriza es de agentes competidores de la industria avícola, y dicha industria no sólo comercializa el pollo, sea éste entero, en cuadriles (que es muslo y pierna), o el menudo del pollo; además conlleva la industria avícola el abastecimiento al mercado nacional de un producto naturalmente vinculado al pollo como lo es el huevo. Sobre los estudios diversos que se aplicó para autorizar esta concentración fueron todos 
focalizados en el pollo y no así en el huevo. Por ende, y apegados a estricto derecho, el huevo quedó al margen de la Resolución y desconocemos cómo será el manejo de este producto de consumo por el agente resultante. A nuestro criterio esto es una delicada omisión que amerita ser apreciada con cuidado. Y que independientemente que lo solicitado por los agentes económicos haya sido referido al mercado del pollo, de manera oficiosa PROCOMPETENCIA debió haber requerido de información acerca de la comercialización del huevo. A nuestro juicio no podrá el agente resultante mercadear de igual forma el pollo que sí está autorizado, con el huevo que no está considerado en ninguna parte de la Resolución de concentración y que no puede dejarse este segmento del mercado avícola, por virtud del orden público e interés social, a interpretación de las empresas. El Derecho de Competencia es materia de Derecho Público, y el Principio de Legalidad Administrativa constriñe al extender una autorización a no ir más allá de lo concedido.

d) El artículo 71 del reglamento en plena consonancia con lo dispuesto en los artículos 6 y 13 de la ley, facultan al Consejo Directivo de PROCOMPETENCIA a fijar Derechos y Tasas por los Servicios, uno de éstos es el de la autorización de concentración empresarial. Teniendo dicha prerrogativa de ley, el Instituto Nacional de Promoción de la Competencia dispuso en la página web, de manera pública y transparente y a la orden de los agentes económicos que quieran concentrarse, un documento que denominan "Guía de Solicitud para Concentraciones Económicas". Dicha guía como su nombre lo indica, tiene la finalidad de orientar el propósito que tiene la concentración y suministrar información a los interesados, de los pasos que se deben seguir a fin de obtener una autorización para concentrarse. En la parte final del mencionado documento propiamente en la página $27 \mathrm{del}$ mismo, se indica el costo que tiene dicho trámite, que lo estratifican en tres tarifas que están en dependencia de la cuantía de la concentración, en otras palabras cada operación de concentración tiene como resultado unificar a dos o más empresas en un solo agente resultante, las ganancias de las empresas que antes operaban de forma independiente, con la concentración integran sus ganancias, por tanto partiendo el monto inicial de las ganancias unificadas es que se fija el criterio para pagar las tarifas, el primero es el que establece la ley como el mínimo y que está en correspondencia con el 25\% del mercado relevante, de esto se estratifican las tarifas así: en aquellas que resulten hasta 20 millones de dólares en su operación deberán pagar 20 mil dólares americanos para concentrarse; de 20 a 35 millones de dólares, la tarifa es de 35 mil dólares; y finalmente de 35 millones en adelante, deberán pagar 45 mil dólares. 
La teleología de esta disposición atiende a los criterios que, el Estado no cuenta con los recursos suficientes para llevar a cabo un sinnúmero de estudios independientes que precisen los alcances de las concentraciones que se soliciten. Para autorizar una concentración en el área que ésta sea, el Estado no puede ni debe basarse únicamente con los insumos de información que suministran las partes interesadas; todo lo contrario, tanto esas informaciones y todas aquellas que se estimen pertinentes, el artículo 46 del reglamento obliga a la autoridad a investigar, y que el legislador denominó a esta función como Facultades de Investigación, sin embargo éstas conllevan un costo que justifica que el Poder Legislativo otorgara la facultad al Consejo Directivo para establecer dichas tarifas.

Hasta aquí estamos de acuerdo con el cobro de las tarifas, el señalamiento radica en que no se observa en ninguna parte del Expediente que se haya cumplido con esta disposición, la cual es previa y general, y que estableció el Consejo Directivo para los agentes a concentrase. Que no es propio en un procedimiento administrativo ni deducir ni colegir, sino que impera el sistema escrito, y debió haber existido constancia en los Vistos Resulta, que se cumplió con el pago de la tarifa establecida.

\subsection{Las imprecisiones de la Resolución}

a) En el inciso e) de la Parte Resolutiva referido a la estabilidad laboral, la terminología que utiliza el Presidente del Instituto Nacional de Promoción de la Competencia son nominaciones que son propias de las empresas que se están concentrando, pero no son las mismas con las que se expresa el Código del Trabajo. De tal manera que encontramos términos tales como "trabajadores de base", "niveles gerenciales" y "niveles administrativos", que son criterios de clasificación con que las compañías avícolas denominan a sus trabajadores. Pero consideramos que no corresponde al Estado plegarse a dicha terminología, sino al contrario, observar primeramente la legislación nacional vigente y más aún aquella que tiene criterios de especialidad como es el caso de la Ley 185 que es Código del Trabajo; este cuerpo normativo establece quiénes son los sujetos del Derecho del Trabajo y éstos están comprendidos en los artículos 6 al 12, es obligación de todo órgano del Estado referirse con los criterios que establece el Código del Trabajo independientemente que a lo interno de los organigramas empresariales se adopte otro tipo de términos o nombres.

b) En el inciso f) de la Resolución se comete un error que por lo craso es más aducible pensar que fue un lapsus en la proyección de la Resolución que un error de derecho, por lo elemental del mismo, pero al final no puede 
pasarse por alto en una misión de análisis como a la que estamos avocados; se ordena en este inciso la desconcentración de una marca utilizada por uno de los agentes solicitantes como lo es la marca Pollo Real. En su análisis el órgano de competencia estima saludable para la economía que dicha marca sea ofrecida en venta. Pero para ello le ordena a una sociedad anónima que la venda por licitación pública. Los comentarios al respecto son evidentes. No puede utilizar la licitación pública el sector privado bajo ninguna modalidad. La licitación pública es de la esfera exclusiva del Estado en todas sus manifestaciones, sea que se trate de entes centralizados, descentralizados, desconcentrados o autónomos. La Ley 737, Ley de Contrataciones Administrativas del Sector Público en su artículo 3, de manera pormenorizada indica qué se debe entender por Sector Público, y obviamente esto excluye por su propia naturaleza a cualquier ente que se rija por el Derecho Privado, exceptuando a aquellos que reciben alguna participación del erario público, o bien que se constituyeron en empresas mixtas. Por otra parte, la mencionada ley nos indica qué es propiamente la licitación en las definiciones del artículo 2: "Licitación: Es el procedimiento administrativo de carácter concursal mediante el cual el órgano o entidad del Sector Público realiza un llamado público, convocando a los interesados para que, sujetándose al pliego de bases y condiciones, formulen propuestas, de entre las cuales seleccionará y aceptará la mejor oferta”. No puede ordenar PROCOMPETENCIA que un agente económico del sector privado venda por licitación pública.

c) En el punto 2 de la Resolución, el órgano de competencia advierte que de encontrar indicios que se suministró información falsa o incompleta impugnará la presente concentración. La figura de la impugnación está dada para los administrados frente a las decisiones de la Administración, que con la utilización de los recursos tienen la capacidad de rechazar las resoluciones tomadas por los entes estatales. No corresponde a un órgano del Estado impugnar sus propias resoluciones. Está mal empleado el término y debió haberse expresado en el sentido que, de encontrarse información falsa o incompleta anulará o revocará la resolución dictada, dejándola sin efecto legal alguno. Y en cambio, consideramos que sí se debió haber precisado qué tipo de anulación o revocación procedería en este caso, si ésta tendría que ser ex nunc, es decir a partir de su declaración de nulidad o revocación, o si debe ser ex tunc, que sería a partir del día que se dictó la autorización.

d) En el Recurso de apelación contra la Resolución o001-2010 interpuesto por el Representante Legal del organismo de los consumidores INDEC, Instituto Nacional para la Promoción y Defensa de los Derechos de los Consumidores, con fecha o9 de Mayo del corriente año, el Consejo Directivo 
de PROCOMPETENCIA que es la instancia determinada por ley para evacuar dichos recursos, en la Resolución Administrativa CDP-0002-2011 con la cual responden al Recurso de Apelación, en el inciso II de los Considerandos de la misma, concede intervención como si fuese sujeto del procedimiento, a uno de los agentes a concentrarse, y no sólo les da intervención sino que los denomina como parte recurrida, cuando es inequívoca la posición de la doctrina, que sólo son recurribles los actos de la Administración. El agente económico, no desaprovecha el yerro del Consejo Directivo y procede a alegar y contra argumentar los criterios apelados por INDEC. Al respecto debemos indicar que sobreabunda en la doctrina y en especial del Derecho Administrativo, que los recursos son mecanismos de control de los administrados hacia la Administración, por ende la parte recurrida no puede ser jamás uno o ambos de los agentes que están solicitando concentración y que ya se les otorgó la autorización, en tanto que el recurrido es el Estado de Nicaragua en su órgano de competencia por la Resolución de autorización de concentración que éste dictó. No puede ser parte demandada de un recurso administrativo un elemento exógeno del Estado. Y aunque para efectos de evacuar esta Resolución de Apelación resultaron intrascendentes los alegatos de los agentes solicitantes, bajo ningún concepto se les debió haber dado participación, por tanto que INDEC demostró ser un tercero administrativo, que fueron reconocidos como tales al demostrar un interés legítimo y consecuentemente se dio cabida para que interpusieran tanto un recurso de revisión, como de apelación. Los sujetos de un recurso administrativo son dos: quien recurre y contra quien se recurre, en otras palabras el administrado y la Administración, nada más.

Parece que la Resolución Administrativa CDP-0002-2011 confunde el Principio de Oficialidad que obliga a la Administración Pública dentro de un procedimiento administrativo a impulsar los trámites, y que es un imperativo hacerlo desarrollando las actividades que sean necesarias para llegar a la decisión final, sin necesidad que sea excitada en este sentido por los particulares (Escorcia, p. 200). Con lo que se da en el ámbito del Derecho Civil en cuya jurisdicción impera el Principio Dispositivo, siendo la jurisdicción civil rogada ya que el proceso, -no el procedimiento-, es cosa de las partes de quienes depende su tramitación.

\subsection{El Principio de Legalidad Administrativa en la Resolución}

a) En el inciso c) de la Resolución se ordena como una condición pendiente de seguimiento, que el agente económico resultante deba pagar por el término de 3 años, la cantidad anual de 50 mil dólares americanos con la finalidad de que sean destinados a las Asociaciones de Consumidores legalmente 
constituidas, con el propósito que se capaciten en materia de Fortalecimiento del Consumo Responsable y Seguridad Alimentaria. Llega incluso a expresar este inciso que esta condición sujeta a seguimiento, es "una contribución y fortalecimiento a la asignación que el Estado de Nicaragua realiza con estas Asociaciones de Consumidores". Y agrega más adelante que esta condición es para dar cumplimiento a lo ordenado en la Ley 182, Ley de Defensa de los Consumidores. El primer señalamiento que salta a la vista es que no puede ordenarse una contribución; o es el cumplimiento de un mandato o es la espontánea voluntad desprovista de condicionamientos de quien desea contribuir en lo que estime pertinente. Pero más importante que esta consideración, es analizar qué sucede con esta orden del Instituto Nacional de la Promoción de la Competencia.

No fue ubicable por más y que se escudriñó, ningún artículo, sea en la ley o en el reglamento, que sustente esta decisión de obligar a pagar un monto dirigido a organismos de defensa del consumidor.

Forzó la Resolución para justificar una disposición legal, el trasladar la sustentación jurídica a la esfera o ámbito de la Ley 182, Ley de Defensa de los Consumidores. Aunque las intenciones sean buenas, existe una invasión en la competencia de otro órgano del Estado. Un ente autónomo como es PROCOMPETENCIA invade lo que corresponde a un ente centralizado al Poder Ejecutivo como es la Dirección de Defensa de los Consumidores del Ministerio de Fomento, Industria y Comercio. La autoridad de competencia debe actuar dentro de la esfera jurídica que le corresponde, como lo debe de hacer la Dirección de Defensa de los Consumidores, como autoridad competente dentro de su área delimitada por la Ley.

El establecimiento de esta condición para que se autorizara la concentración avícola, encaja a la perfección en lo que técnicamente se denomina Desvío de Poder. Que es el actuar dentro de un marco jurídico de un modo exagerado en el uso de las facultades discrecionales. "Desvirtuando la finalidad del acto administrativo, es decir, que existe desviación de poder, cuando en una actuación lícita de la Administración, ésta ha desviado el fin de una actuación concreta a otro igualmente válido, pero no previsto para el caso concreto". (Escorcia, p. 149)

Siendo la facultad discrecional un actuar reglado, con esta condición que estableció la Resolución, se exorbitó de los parámetros y propósitos para la cual fue concebida la normativa de Competencia. Y aunque el Art. 2, Inc. 6 de la Ley 350, Ley Reguladora de la Jurisdicción Contenciosa Administrativa, a la letra dice: "Desviación de Poder: Es el ejercicio de 
potestades administrativas para fines distintos de los establecidos por el ordenamiento jurídico o que no concordaren con el logro del interés público y el bien común." Si bien reconocemos que se pretende con esta condición proporcionar un financiamiento económico que se distribuya por la vía del Presupuesto General de la República, para contribuir al bien común, capacitando debidamente a los organismos de defensa de los consumidores, PROCOMPETENCIA no está facultada para tomar tal determinación.

b) En el inciso f) de la Resolución se ordena al agente económico resultante la venta de la Marca Pollo Real. Esta orden es muy peculiar en tanto que da un plazo de un año para que se efectúe dicha venta, y transcurrido este término si no se vendió, vuelve al haber del agente económico resultante. Entendemos plenamente que lo que pretende el Instituto Nacional de Promoción de la Competencia con esta condición, es propiciar a que se amplíe la competencia de este mismo producto avícola y que para ello las dos compañías que ya están consolidadas en el mercado relevante, se desprendan de una marca también reconocida a efectos que la competitividad y el libre mercado se hagan efectivos. Pero dar a esta condición el plazo de un año, para nuestro criterio es una medida un tanto cosmética por la brevedad del término si verdaderamente la pretensión es venderla.

En un segundo señalamiento siempre en este inciso de la Resolución, se expresa en esta orden una disposición que es un deber ponerla de manifiesto en este análisis. Se dispone que dicha venta sea ofrecida solamente a un tercer competidor potencial no nacional. Para nosotros esto es delicado, se está diciendo que se excluya por ende a un eventual comprador nacional, y la adopción de esta posición y proviniendo de un ente estatal, es crear por disposición de una resolución un criterio que rompe con el Principio de Igualdad consagrado en la Constitución Política del país. La medida es congruente sólo si nos ubicamos en términos del campo de la economía y más concretamente de la macroeconomía; eso lo expresamos porque PROCOMPETENCIA está claro que, atrás de cada una de las empresas nacionales que se fusionaron, es decir Tip Top y Pipasa, están transnacionales que son partícipes accionarias de las empresas nacionales. Tiene la intención la autoridad de competencia abrir deliberadamente un espacio que propicie más competitividad y así fomentar un libre mercado que ofrezca al consumidor un producto que por su posicionamiento en el mercado, resulte de buena calidad y a un precio más bajo. Repetimos, esta medida tiene lógica si la vemos sólo partiendo de una deliberación de las ciencias económicas pero contrarían no sólo la igualdad jurídica, sino la libertad de empresa, que pasa, como dice el Dr. Herrera, por la libertad de acceso al mercado (Herrera, p. 28). 
Dejando de manifiesto esta inconsistencia, nos preocupa que si sólo se tratase de aplicar la Ley 601 y su Reglamento, el gran propósito que ésta tiene es el de remover obstáculos legales y económicos para garantizar la libertad de empresa. La finalidad de toda la filosofía del Derecho de la Competencia radica en procurar un espacio propicio para que quien desee ingresar a competir en el mercado lo haga. Si la lógica de PROCOMPETENCIA fue la de pensar en otro agente transnacional lo suficientemente poderoso económicamente hablando, como para efectuar una verdadera competencia frente a Cargill y Rica Foods, y por ende dentro de esa concatenación de pensamiento se concluyó que no existe en los empresarios nacionales ninguno económicamente fuerte como para contrarrestar el poder de estas transnacionales, también se debió haber visto la realidad demostrada en este mismo Expediente, que tras las empresas nacionales solicitantes de concentración, están empresas multinacionales; entonces, por qué no permitir que otra empresa multinacional participe de una empresa nacional ya existente, como podría ser Pollo Estrella, Pollo Rico o CAPEQ, o incluso la formación de otra nueva empresa nicaragüense con capital nacional. No tenemos otra opción que considerar que esta decisión del órgano de competencia establece de forma expresa y por escrito, una barrera de acceso para el mercado avícola a los agentes nacionales, que es a todas luces una acción anticompetitiva.

c) En el inciso g) de la Resolución se ordena a los agentes solicitantes que en el instrumento legal en que se formalice la concentración, consignen en el mismo una cláusula impuesta de forma condicionada por esta Resolución y que se denomina "Cláusula de No Competencia". Esta cláusula que se estila en las autorizaciones de concentración empresarial en otros países y se hace más común en aquellos que conforman la Unión Europea, consiste en una obligación de no hacer, que suele asegurarse con una estipulación penal de pagar equis cantidad en caso de incumplimiento. El propósito de esta Cláusula que se da entre los agentes, tanto el que compra como el que vende, y de cuya transacción surge un agente económico resultante, se redacta en el sentido que el agente que salga del mercado, se abstenga de competir con el que acaba de comprar para dar un margen razonable para que éste recupere la inversión y no se vea expuesto a competir con un nuevo agente que pueda crear el que vendió, y que capitalizando su experiencia en el mercado impida que el agente resultante expanda sus planes económicos que fueron los que motivaron la concentración. De tal manera que pactan para no crear competencia por un margen de tiempo razonable que se determine en la cláusula. 
El hecho que el contenido de una cláusula sea el de no hacer o abstenerse de hacer, por supuesto que no contraría nuestro ordenamiento jurídico. En base al Principio de Libertad Contractual, una cláusula de no competencia como lo es ésta, mientras sea dada en uso de esa libertad de las partes, éstas pueden pactarla sin inconveniente, siempre y cuando lo pactado sea posible y además lícito. Refiriéndose a las "prohibiciones contractuales de no competir", el jurista español Joaquín Garrigues en su obra Cursos de Derecho Mercantil, al respecto nos dice:

...estos pactos se hacen:a) en operaciones deventa o arrendamiento de una empresa como complemento de la obligación de transmitir la cartera de clientes; b) con motivo de la separación de un socio o un empleado de una empresa para evitar la competencia desleal contra la misma empresa, y c) entre empresas dedicadas al mismo ramo para evitar la competencia entre sí. Antes de la publicación de la ley española de competencia (1963), se entendía que tales pactos eran admisibles, siempre que contuvieran una limitación, en el espacio y en el tiempo. La situación cambió al publicarse dicha ley, pues entonces deben ser analizadas desde el punto de vista de si son o no obstáculos a la libre concurrencia. (Garrigues, 1987, p. 232)

En nuestro criterio existe una línea muy fina en el sentido que si esta cláusula riñe o no con la libre competencia. En sí, es una restricción a la competencia pactada por las razones ya expuestas, que aunque se justifiquen por la aquiescencia de las partes en convenirla, no deja de ser una limitación al acceso y participación en el mercado avícola. Este sería un primer señalamiento.

El segundo, que es el que da pie a un cuestionamiento, y que radica en que esta Cláusula de No Competencia si se lee literalmente de lo escrito en la Resolución, no pareciera nacer motivada en el seno del Derecho Privado, que es donde tiene cabida el Principio de Libertad Contractual, sino que da la impresión de ser impuesta en forma de condición por la autoridad de competencia de Nicaragua; no obstante, de una lectura cuidadosa, lo que se limita es un acuerdo, es decir que las partes habían convenido dicha cláusula y que PROCOMPETENCIA sólo la disminuyó al limitarla en el tiempo en 36 meses. Sin embargo esto, por profilaxis jurídica debió haber quedado con una redacción más clara. Aún así el referirse a una Cláusula de No Competencia nos da pie a la presente reflexión. 
La facultad legal para ordenar esta disposición tiene su asidero en el artículo 51 de la Ley de Competencia que establece al Derecho Común como norma supletoria en los aspectos no previstos por la Ley 601. Y se tuvo que utilizar necesariamente el criterio del artículo 443 del Código de Procedimiento Civil que está previsto para llenar los vacíos jurídicos y lagunas legales y que en un orden de prelación está la "legislación análoga extranjera". Sucede sí que la práctica tanto en Europa como en México y Argentina entre otros países, que el órgano de competencia utilice esta Cláusula de No Competencia, no está sustentada en el derecho positivo sino en la práctica legal o en la costumbre. Pero para el Derecho Administrativo en Nicaragua, la costumbre no es fuente de Derecho en tanto que impera el Principio de Legalidad Administrativa. Y sólo tiene cabida la costumbre mercantil, que es propia del Derecho Privado y en casos excepcionales. Por tanto concluimos que esta decisión es comprensible pero difícil de sustentarla legalmente.

d) En el Recurso de Apelación dictado por el Consejo Directivo de PROCOMPETENCIA, en el punto 2 de la parte resolutiva, modifica para mejorar los literales b), c) y e) de la Resolución Administrativa dictada por el Presidente del Instituto Nacional de Promoción de la Competencia. Independientemente del contenido de las mejoras de forma que consideró el Consejo Directivo, utilizó el Recurso de Apelación para modificar la Resolución Administrativa sin tener facultades expresas para hacerlo. En la resolución de un recurso administrativo, la instancia que resuelve está obligada a pronunciarse en todos y cada uno de los puntos que son recurridos, estimándolos individualmente y dándoles lugar o no. Pero de ahí a mejorar el contenido de la Resolución en puntos que no fueron recurridos, es un actuar que no está fundado en ley alguna.

Existe en la Doctrina un acto denominado Revisión de Oficio por la Administración y que tiene cabida su aplicación dentro del Recurso de Apelación para ampliar o rectificar el contenido de una Resolución Administrativa, sin embargo para que esto opere, como nos dice Jesús González Pérez en su obra Manual de Derecho Procesal Administrativo (González, p. 241), la Revisión de Oficio por la Administración debe estar autorizada por ley expresa para que sea aplicada, y son escasos los países latinoamericanos en donde opera, como lo es en la República de Chile.

De tal manera que nos resulta invasivo tal actuar del Consejo Directivo en la esfera que corresponde al Tribunal de lo Contencioso Administrativo, el que sí tiene facultades para reponer, reformar y aclarar el contenido de una Resolución Administrativa. 


\section{Conclusiones}

1. Pertinencia normativa en la legislación nacional de Competencia, en particular en el ámbito de concentración empresarial. Partiendo del análisis de esta concentración avícola que se constituyó en el primer antecedente en su tipo, podemos manifestar fundamentados en este estudio que en términos generales, se aplicaron los mejores criterios que faculta la Ley y el Reglamento al Instituto Nacional de Promoción de la Competencia. Que se autorizó debidamente la solicitud de los agentes y con ello se realizó plenamente el presupuesto de ley reglado para tal propósito.

2. Consecuencia inmediata de la autorización, percibimos un estímulo en el sector empresarial. Denotando esta satisfacción al alcanzar sus pretensiones con el incremento de 27 millones de dólares en el desarrollo del negocio avícola en Nicaragua, en un plan quinquenal que parte del presente año. Se evidencia como consecuencia de la autorización de concentración, la dinamización y estimulo de la economía del país. Que este primer precedente administrativo es un incentivo e invitación para que las empresas que tienen concentraciones de hecho se legalicen y aquellas que pretendan expandirse, puedan ocurrir con confianza a realizar la operación de concentración ante PROCOMPENTENCIA.

3. Salvaguardando los intereses de la Nación y reforzando los Principios de Legalidad Administrativa y Seguridad Jurídica se insta al órgano de competencia a superar los aspectos de forma señalados en el análisis estructural del presente estudio, así como los criterios de fondo que están contenidos en el análisis jurídico de la presente investigación.

4. Cuantificando los niveles de la presente concentración que es el de un aproximado del $61 \%$ del mercado relevante, no constituye dicho porcentaje por sí mismo ni un monopolio, ni una práctica anticompetitiva. Como consecuencia de los convenios de colaboración entre los órganos de Competencia a nivel regional, están documentados en los compartimentos del Expediente de esta autorización, que en Centroamérica los niveles de concentración del mercado avícola son: en Costa Rica del 75\%; en El Salvador del 65\%; en Guatemala es de 57\% y en Honduras del 51\%. Que en los Estados Unidos de Norteamérica existe un nivel de concentración del mercado avícola del $78 \%$ sin que esto constituya una práctica antitrust en la legislación de dicha confederación.

5. Concluimos que no existe derogación tácita de normas sino complementación legal al tratamiento que prescribe el Código de Comercio en el articulado 
de la Sección VI que trata "De la fusión y prórroga de las Sociedades Anónimas”. Que únicamente tienen el requisito administrativo que exige el artículo 25 de la Ley 601 para autorización, las empresas que por la fusión alcancen un incremento del mercado relevante superior al de un $25 \%$, o que los ingresos brutos combinados superen un promedio de 642,857 salarios mínimos. Autorizadas las empresas que calcen en este presupuesto de ley, podrán proceder, como requisito sine qua non con lo que dispone el Código de Comercio.

6. Constituye una exigencia para el Instituto Nacional de Promoción de la Competencia velar por que se cumpla con el Principio de Confidencialidad que establece la Ley 601. El cual no debe ser vulnerado más que por requerimiento judicial. Que de surgir un tercero administrativo, éste puede sólo aportar al Expediente los criterios de hecho o de derecho en donde sustente su eventual afectación, mas nunca extraer del Expediente información protegida por la confidencialidad en tanto que sería vulnerar dicho Principio así como el velo societario con que están protegidos los agentes económicos en su conformación legal.

7. Procurar mecanismos que agilicen los trámites para que el Comité Técnico delegado por el Presidente del Instituto para efectuar las funciones de instruir el procedimiento, verificar los análisis técnicos y proyectar una resolución, dispongan del tiempo suficiente para sustanciar debidamente la autorización. La adopción de una fórmula de solicitud tipo, que sirva para cualquiera de los agentes sin importar a qué índole de mercado pertenezcan. Con ello se cumple la ley y se optimiza el tiempo para el Comité. Sin menoscabo que puedan requerir más allá de la fórmula, de mayor información adicional.

\section{Recomendaciones}

1. Facultado que es el Consejo Directivo en base al artículo 13 inc. h de la ley, y relacionando éste al artículo 30 segundo párrafo de la Ley 601, debe dictar un protocolo interno destinado al manejo de la información confidencial a que se refiere el Artículo 47 del Reglamento. Que contenga prefijados los criterios de aceptación o rechazo de lo que deba estimarse como confidencial, en tanto que no todo lo solicitado como tal lo será. Para ello resultaría efectivo la elaboración de un protocolo interno con criterios mínimos que brinde al Presidente de PROCOMPETENCIA consideraciones estimatorias para aceptar la protección del Principio de Confidencialidad a la información requerida, así como la garantía que se cumplirá ya estando bajo la declaratoria de confidencialidad. El Derecho de Competencia es un 
derecho público y las declaraciones de confidencialidad otorgadas deben ser la excepción dentro del expediente, mas no así la regla.

2. Siendo el Instituto Nacional de Promoción de la Competencia un órgano cuya naturaleza comprende la estabilidad de la economía nacional en el control de los agentes de mercado por una parte, y la satisfacción del bien común que comprende a los consumidores finales, el balance de estos criterios en inicio de intereses contrapuestos, al momento de ser sujetos a la autoridad, ésta debe observar con especial esmero los mandatos constitucionales de Legalidad Administrativa contenidos en los artículos 130.1, 160 y 183 de la Constitución Política; para evitar así que se desande por la vía contenciosa administrativa o por la vía constitucional, las resoluciones que no se encuentren debidamente apegadas a la ley. El trato que tuvo la concentración avícola dentro del Recurso de Apelación para mejorar la Resolución, podría tener consecuencias de nulidad. Por ende estos criterios de legalidad deben ser cuidadosamente atendidos a fin de brindar seguridad jurídica de las resoluciones a la clase empresarial nacional e internacional.

3. Instruir debidamente la operación de concentración que soliciten los agentes, exige un esfuerzo de gran proporción que inicia en los aspectos jurídicos pero que pasa obligatoriamente por los estudios económicos y de mercadotecnia que proporcionan las partes interesadas, así como los requeridos a otros agentes de mercado y a distintos entes del Estado. Por lo tanto se hace imperativo brindar al Comité Técnico designado, las mayores condiciones para que el resultado de sus funciones sirva de sustento sólido para que el Presidente y el Comité Directivo en su caso, autoricen la concentración empresarial, con la certeza que se cumplen las expectativas que informan la Ley 601 y su Reglamento. Para optimizar los mecanismo prescritos por la ley y facilitar la instrucción del expediente, la autoría del presente trabajo investigativo propone al Instituto Nacional de Promoción de la Competencia adoptar una fórmula de solicitud para las operaciones de concentración, que pueda ser denominada como "Fórmula UCA - Solicitud de Concentración de Empresas", y que simplifique los 17 requerimientos que en esta primera concentración tuvo que efectuar el Comité por medio de autos. El Consejo Directivo tiene las facultades que proporciona la Ley para establecer las bases normativas necesarias para la aplicación de la Ley de Competencia. La adopción oficial de esta Fórmula acercaría la academia con la institución, evidenciando que se incorporan los mejores criterios investigativos y doctrinales para el fortalecimiento institucional que brinde una mayor seguridad jurídica y agilización efectiva para las empresas a concentrarse. El contenido que deben de llenar en esta Fórmula los agentes solicitantes, están debidamente fundamentos con los criterios que da la Ley 
y el Reglamento. A continuación se presenta la "Fórmula UCA - Solicitud de Concentración de Empresas".

\section{Lista de referencias}

\section{Libros:}

Abboud Castillo, N. \& González Riega, G. (2010). Derecho Concursal. Trabajo presentado en la V Maestría en Derecho de Empresas con especialización en Asesoría Jurídica, Managua, 15-26 marzo, (paper).

Arríen, J. B. (2009). DERECHO ADMINISTRATIVO: Acto, Procedimiento, Recursos, Contratos y el Contencioso-Administrativo. Managua: UCA

Escorcia, J. F. (2002). Derecho Administrativo. León: Editorial Universitaria.

Garrigues, J. (1987). Curso de derecho mercantil. (7ª ed.). Bogotá: Temis

González Pérez, J. (1992). Manual de Derecho Procesal Administrativo. (2 ed.). Madrid: Civitas.

Herrera Espinoza, J.J.(2008).El Derechodela Competencia enelOrdenamiento Jurídico Nicaragüense. Managua: EJ-EDUPOLI

Herrera, J.J. (2004). Análisis de la Constitución Económica Nicaragüense con Especial Referencia a la Libertad de Empresa. Revista de Derecho, (9) pp. 83-86.

López, C.M. (1997). Concepto y Naturaleza del Procedimiento Administrativo. Revista Encuentro, (2).

Miranda Serrano, L. (1994). Las concentraciones económicas, Derecho europeo y español. Madrid: La Ley

Orúe Cruz, J. R. (2008). Derecho de Competencia: Una introducción. Managua: Lea Grupo Editorial.

Orúe Cruz, J. R. (2008). Manual de Derecho Mercantil. (2 ${ }^{\mathrm{a}}$ ed.). Managua: Hispamer.

Rojas Mercado, R. L. \& Mena Flores, A. P. (2006). DEL DERECHO DE COMPETENCIA: El fenómeno de la concentración de empresas. Tesis de Derecho no publicada, Universidad Centroamericana. Nicaragua. 
Escobar Cerda, M. J. (2008). Análisis a la Regulación de las Concentraciones de Empresas en el Marco Jurídico de la Ley 601. Tesis de Especialización no publicada, Universidad Centroamericana. Nicaragua.

Instituto Nacional de Promoción de la Competencia. (2009). Guía para Solicitud de Concentraciones Económicas. Managua: PROCOMPETENCIA. Recuperado el 04 de Julio del 2011, de http://www.procompetencianic. org/documentacion/guias-procompetencia/Guia_Solicitud_ Concentraciones.pdf

Instituto Nacional de Promoción de la Competencia. (2009). RESOLUCIÓN ADMINISTRATIVA CONCENTRACION ECONOMICA Expediente No. OOO1-201O. Managua: PROCOMPETENCIA. Recuperado el o4 de Julio del 2011, de http://www.procompetencianic.org/info/2011/ResolucionFusion-Pipasa-y-Tip-Top.pdf

Instituto Nacional de Promoción de la Competencia. (2009). RESOLUCIÓN ADMINISTRATIVA APELACIÓN CDP-OOO2-2011. Managua: PROCOMPETENCIA. Recuperado el o4 de Julio del 2011, de http://www. procompetencianic.org/info/2011/RESOLUCION-ADMINISTRATIVAapelacionoo01-2010-version-final.pdf

Erickson, P.A. (2011, 11 de abril). Interés de la multinacional Cargill por adquirir Corporación Pipasa en Nicaragua. Diario de Fusiones \& Adquisiciones. Recuperado el o8 de Julio del 2011, de http://www.diariodefusiones. com/?Interes_de_la_multinacional_Cargill_por_adquirir_ Corporacion_Pipasa_en_Nicaragua\&page $=$ ampliada\&id $=323 \& \_s=\&$ _ page $=$ centro_caribe

Navas, L. (2011, 12 de abril). Recurren contra fusión avícola. Diario La Prensa. Recuperado el o8 de Julio del 2011, de http://www.laprensa.com. ni/2011/04/12/economia/57481\#.Tk2NixawVmQ

Aguilera, A. (2011, 17 de mayo). Cargill Nicaragua invertirá U\$27 millones. El Nuevo Diario. Recuperado el 11 de Julio del 2011, de http://www. elnuevodiario.com.ni/economia/102365

Herrera, M. (2009, o9 de octubre). ¿'Toda fusión o adquisición es concentración? La Prensa Gráfica de El Salvador. Recuperado el 15 de Julio del 2011, de http://www.laprensagrafica.com/economia/nacional/64887--itodafusion-o-adquisicion-es-concentracion.html 


\section{Normativa nacional:}

Constitución Política de Nicaragua, publicada en La Gaceta, Diario Oficial, No. 68, del 9 de abril de 2005

Código de Comercio de la República de Nicaragua y sus reformas (2003). Managua: Hispamer

Código de Penal de la República de Nicaragua, publicado en La Gaceta, Diario Oficial, Nos. 83, 84, 85, 86 y 87 del 5, 6, 7, 8 y 9 de Mayo del 2008

Ley 182, "Ley de Defensa de los Consumidores", publicada en La Gaceta, Diario Oficial, No. 213, del 14 de noviembre de 1994.

Ley 350, "Ley de la Jurisdicción de lo Contencioso Administrativo", publicada en La Gaceta, Diario Oficial, Nos. 140 y 141, del 25 y 26 de julio de 2000.

Ley 601, "Ley de Promoción de la Competencia", publicada en La Gaceta, Diario Oficial, No. 206, del 28 de septiembre del 2006.

Reglamento a la Ley 601, "Ley de Promoción de la Competencia”, Decreto No. 79-2006 publicado en La Gaceta, Diario Oficial, No. 10, del 15 de enero del 2007.

\section{Normativa internacional:}

Decreto Legislativo No. 1033, "Ley de Organización y funciones del Instituto Nacional de Defensa de la Competencia y de la Protección de la Propiedad Intelectual". Publicado en El Peruano, Diario Oficial del Perú, del 25 de junio del 2008

Ley No. 7472, "Ley de Promoción de la Competencia y Defensa Efectiva del Consumidor”, publicada en el Diario Oficial, La Gaceta de Costa Rica, No. 14 el 19 de enero de 1995.

Reglamento a la Ley 7472, "Ley de Promoción de la Competencia y Defensa Efectiva del Consumidor”, Decreto No. 25234 publicado en La Gaceta, Diario Oficial, No. 124, del 01 de julio del 2006. 